\title{
Observations of polar patches generated by solar wind Alfvén wave coupling to the dayside magnetosphere
}

\author{
P. Prikryl ${ }^{1}$, J. W. MacDougall ${ }^{2}$, I. F. Grant ${ }^{2 *}$, D. P. Steele ${ }^{3}$, G. J. Sofko ${ }^{3}$, R. A. Greenwald ${ }^{4}$ \\ ${ }^{1}$ Communications Research Centre, 3701 Carling Ave., Box 11490, Station H, Ottawa, Ont. K2H 8S2, Canada \\ ${ }^{2}$ Department of Physics and Astronomy, University of Western Ontario, London, Ont. N6A 5B9, Canada \\ ${ }^{3}$ Institute of Space and Atmospheric Studies, University of Saskatchewan, Saskatoon, Sask. S7N 5E2, Canada \\ ${ }^{4}$ The Johns Hopkins University Applied Physics Laboratory, Laurel, MD 20723-6099, USA
}

Received: 19 March 1998 / Revised: 4 September 1998 / Accepted: 18 September 1998

\begin{abstract}
A long series of polar patches was observed by ionosondes and an all-sky imager during a disturbed period $\left(K_{p}=7\right.$ - and IMF $\left.B_{z}<0\right)$. The ionosondes measured electron densities of up to $9 \times 10^{11} \mathrm{~m}^{-3}$ in the patch center, an increase above the density minimum between patches by a factor of $\sim 4.5$. Bands of F-region irregularities generated at the equatorward edge of the patches were tracked by HF radars. The backscatter bands were swept northward and eastward across the polar cap in a fan-like formation as the afternoon convection cell expanded due to the IMF $B_{y}>0$. Near the north magnetic pole, an all-sky imager observed the 630-nm emission patches of a distinctly band-like shape drifting northeastward to eastward. The $630-\mathrm{nm}$ emission patches were associated with the density patches and backscatter bands. The patches originated in, or near, the cusp footprint where they were formed by convection bursts (flow channel events, FCEs) structuring the solar EUV-produced photoionization and the particle-produced auroral/cusp ionization by segmenting it into elongated patches. Just equatorward of the cusp footprint Pc5 field line resonances (FLRs) were observed by magnetometers, riometers and $\mathrm{VHF} / \mathrm{HF}$ radars. The AC electric field associated with the FLRs resulted in a poleward-progressing zonal flow pattern and backscatter bands. The VHF radar Doppler spectra indicated the presence of steep electron density gradients which, through the gradient drift instability, can lead to the generation of the ionospheric irregularities found in patches. The FLRs and FCEs were associated with poleward-progressing DPY currents (Hall currents modulated by the IMF $B_{y}$ ) and riometer absorption enhancements. The temporal and spatial characteristics of the VHF backscatter and associated riometer absorptions closely resembled those of poleward moving auroral forms (PMAFs). In the solar wind, IMP 8
\end{abstract}

\footnotetext{
* Present address: CSIRO Division of Atmospheric Research, Aspendale, VIC 3195, Australia

Correspondence to: P. Prikryl
}

observed large amplitude Alfvén waves that were correlated with Pc5 pulsations observed by the ground magnetometers, riometers and radars. It is concluded that the FLRs and FCEs that produced patches were driven by solar wind Alfvén waves coupling to the dayside magnetosphere. During a period of southward IMF the dawn-dusk electric field associated with the Alfvén waves modulated the subsolar magnetic reconnection into pulses that resulted in convection flow bursts mapping to the ionospheric footprint of the cusp.

Key words. Ionosphere (polar ionosphere). Magnetospheric physics (magnetosphere-ionosphere interactions; polar wind-magnetosphere interactions).

\section{Introduction}

The regions of electron density enhancements known as polar patches drifting antisunward in the polar cap ionosphere can be observed by various techniques, principally radio or optical (Crowley, 1996). Initially, polar patches were identified as enhancements in the 630$\mathrm{nm}$ airglow emission due to dissociative recombination of $\mathrm{O}_{2}^{+}$while the enhanced F-region ionization in the polar patches was tracked by sophisticated ionosondes (Buchau et al., 1983; Weber et al., 1984). Scintillation measurements (Buchau et al., 1985) showed that the patches are highly structured and implied the presence of small-scale irregularities with considerable irregularity amplitude (Basu et al., 1994). These techniques, plus total electron content and incoherent scatter radar measurements, were combined to study the structure and dynamics of polar patches (Weber et al., 1986). A review of past research on polar cap patches was presented by Tsunoda (1988). A more recent advance in the study of patches (Crowley, 1996) was brought about by imaging riometers and HF radars that turned out to be rather 
successful in detecting and tracking the patch related absorption and irregularities from the source region near the cusp footprint into the polar cap (Rosenberg et al., 1993; Nishino et al., 1998). The HF radars, together with other techniques, were used to discover some new features of polar patches, such as their close relationship to the cusp and the hemispherical conjugacy (Rodger et al., 1994a, b; Rodger and Graham, 1996).

In spite of these efforts to understand the phenomenon, the question of polar patch formation remains unresolved (Crowley, 1996). Several mechanisms have been proposed and, while each of them can explain some aspects of polar patches, none of them alone seems to provide a complete picture. However, one should keep in mind that several mechanisms may in fact be needed to explain this rather complex phenomenon. Anderson et al. (1988) suggested that a time-varying convection can generate patchiness assuming there is a large solar induced enhancement in the electron density near the convection reversal boundary. When the cross-polar-cap potential rises abruptly, the polar cap expands bringing in sunlit plasma from low geomagnetic latitudes which thereafter convects into the polar cap. The polar cap boundary then retracts, "breaking off" a polar patch. Lockwood and Carlson (1992), using a new concept of flow excitation developed by Cowley and Lockwood (1992), proposed that time-dependent magnetic reconnection and convection produce polar cap patches from pre-existing enhancements of the electron density and associated density gradients produced by solar photoionization near the terminator. They invoked transient bursts of magnetic reconnection, known as flux transfer events (FTEs), in their mechanism of patch production. It should be noted that patches were tentatively associated with FTEs earlier by Walker et al. (1986) who used an HF radar to study pulsations near the cusp. Rodger et al. (1994a) suggested that enhanced ionization of the convecting plasma by particle precipitation in the cusp and subsequent disruption of the convection by flow channel events (FCEs) (Pinnock et al., 1993) can form polar patches.

In models of polar cap patches that rely on the solar induced ionization the problem becomes one of understanding how the patches are produced from a tongue of ionization (TOI) drawn into the polar cap by convection. Sojka et al. (1993) modeled polar cap patches and suggested that they can be formed without a complex plasma source and can occur naturally as the magnetospheric convection varies in time in response to changes in the IMF $B_{y}$ component. As a result, TOIs that are extended into the polar cap become severely distorted (Sojka et al., 1994) but it is not clear whether this distortion can segment TOIs into patches. Valladares et al. $(1994,1996)$ observed and modeled fast plasma jets collocated with regions of low F-region density and enhanced plasma temperature. They concluded that the latter resulted in an enhanced recombination rate thus eroding a substantial volume of the ionization tongue and segmenting it into patches.

There is strong evidence suggesting that patches originate in the dayside auroral (Buchau et al., 1985) or even subauroral ionosphere (Tsunoda, 1988) although these authors emphasized the EUV-produced photoionization plasma as the source of patches. Sojka and Schunk (1986) modeled significant density enhancements produced by soft and hard precipitation in the dayside auroral oval. Enhanced F-region plasma had been observed convecting from the solar-illuminated dayside ionosphere through the cusp region and into the polar cap (Foster and Doupnik, 1984; Foster, 1993; Valladares et al., 1994; Pinnock et al., 1995a). Also, local enhancements of F-region densities in patches which formed near the cusp were attributed to soft electron precipitation (Valladares et al., 1994).

A detailed understanding of the process of coupling between the solar wind and dayside magnetosphere may ultimately be necessary to explain patch formation. In a case study, Prikryl et al. (1998) (hereafter referred to as paper 1) showed evidence for the coupling to the dayside magnetosphere of solar wind compressional waves. Here, we present the results of another case study which indicates that Alfvénic fluctuations in the solar wind couple to the dayside magnetosphere, modulate the magnetic reconnection and drive field line resonances. The coupling process and associated ionospheric signatures are illustrated in Fig. 1 for IMF $B_{y}>0$. It is suggested that the electron precipitation associated with field line resonances (FLRs) equatorward of the cusp can contribute significantly to patch formation. This plasma is then restructured into patches as it convects through the cusp footprint and is drawn into the polar cap. A multi-instrument data base is used to identify the patches and a variety of phenomena that are involved in their formation.

\section{Instruments and techniques}

The Kapuskasing-Saskatoon pair of HF radars (Fig. 2) is a part of an extended network of HF radars called SuperDARN (Super Dual Auroral Radar Network) (Greenwald et al., 1995). The FoV of this pair of radars extends from $65^{\circ}$ to $85^{\circ}$ north magnetic latitude and covers $\sim 4$ hours in magnetic local time. The radars employ linear phased arrays of 16 log-periodic antennas and operate at frequencies between 8 and $20 \mathrm{MHz}$. Each radar forms a beam which is narrow in azimuth $\left(2.5-6^{\circ}\right)$ but broad in elevation (up to $\sim 40^{\circ}$ at $8 \mathrm{MHz}$ ). The beams were stepped through 16 adjacent azimuthal positions every $96 \mathrm{~s}$. In near-real time, the radars measure the backscatter power, line-of-sight velocity and Doppler spectral width by fitting the auto-correlation functions (ACFs) for 70 range bins starting at the slant range of $180 \mathrm{~km}$ (normally with the range resolution of $45 \mathrm{~km}$ ).

The Canadian Advanced Digital Ionosonde (CADI) installed at Rabbit Lake, Resolute Bay and Eureka observed patches drifting overhead. Each CADI (MacDougall et al., 1995) uses a receiving antenna array consisting of four dipoles arranged along the sides of a square $60 \mathrm{~m}$ on a side, with each antenna attached to a dedicated receiver. A fixed transmitter frequency mode 


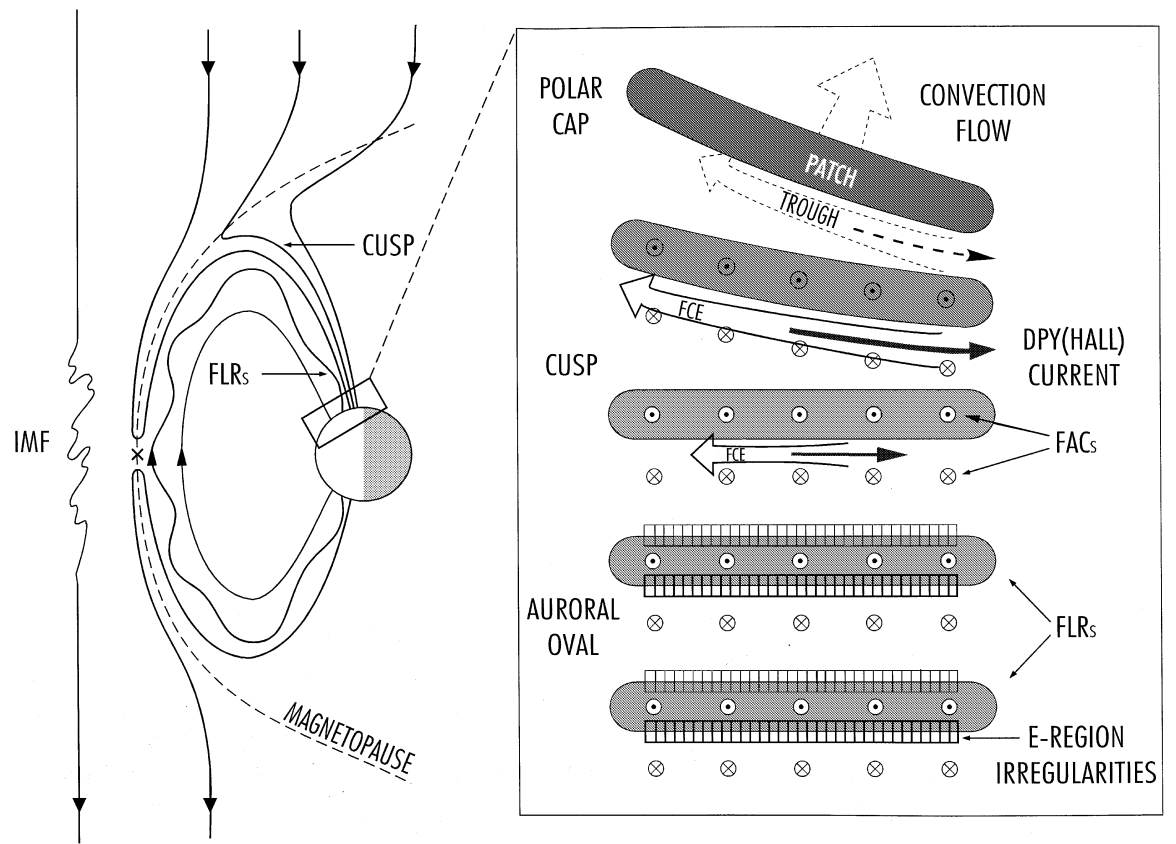

Fig. 1. Schematic representation of the solar wind-magnetosphere-ionosphere coupling and generation of polar patches. Several phenomena and causal relationships that are portrayed in this figure are supported by the data presented in the case study (December 2, 1993): the interplanetary magnetic field $(I M F)$ and solar wind Alfvén waves (Fig. 3), ionospheric cleft $(D P Y)$ currents (Fig. 5), field line resonances (FLRs) (Figs. 6, 8, 12, and 13), field aligned currents (FACs) and the ionospheric structure equatorward of the cusp footprint (Figs. 7, 8, 9, and 10), pulsed magnetic reconnection (flux transfer events, FTES) at the subsolar magnetopause, flow channel events (FCES) and polar patch formation near the cusp footprint (Figs. 8 and 16), polar cap convection (Fig. 15), and patches convecting in the polar cap

(Figs. 14, 17, 18, and 19)

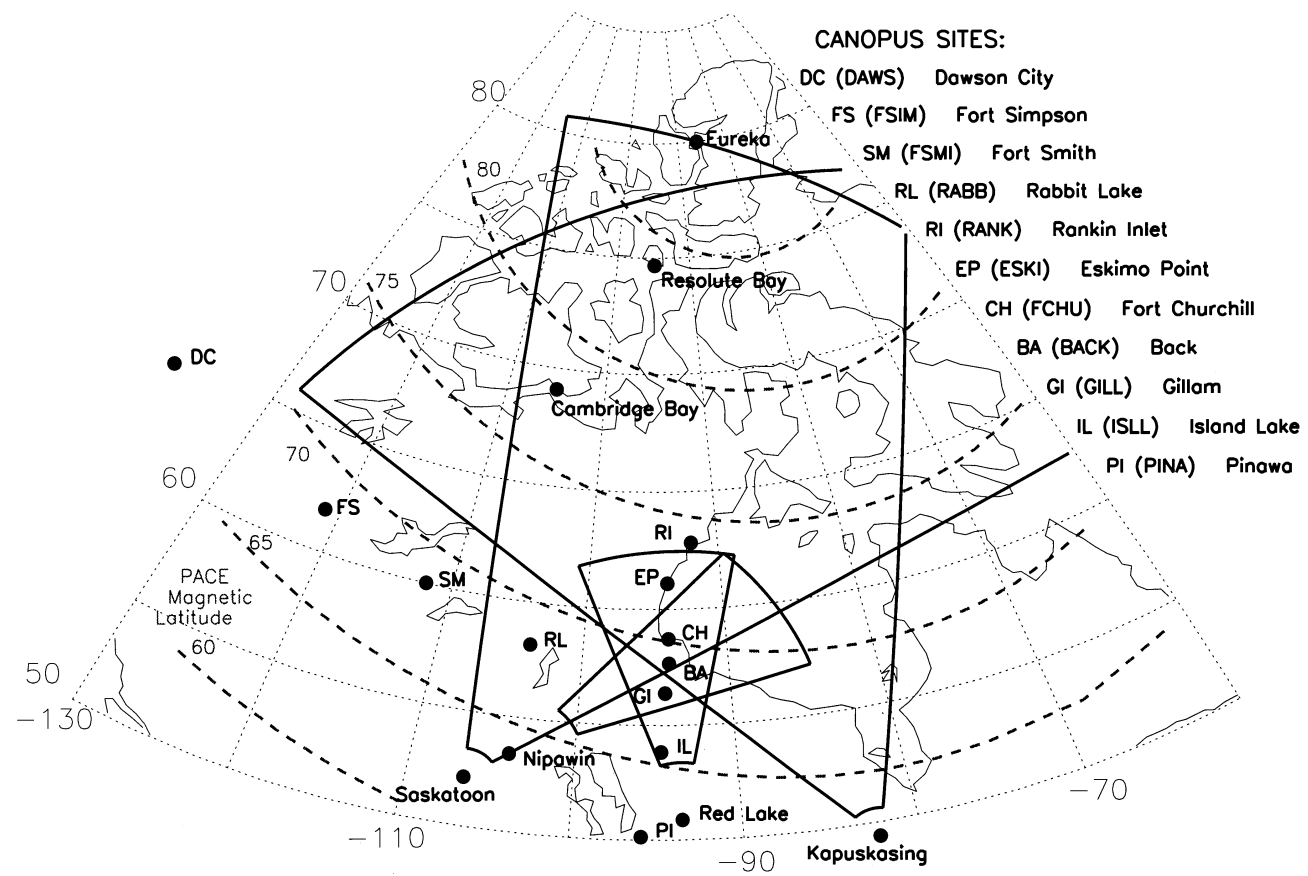

Fig. 2. The locations and fields of view of the SuperDARN Kapuskasing-Saskatoon and BARS Nipawin-Red Lake radars projected onto a map that is also showing some of the CANOPUS and CADI sites. The all-sky imager was located in Eureka (usually three frequencies) was interleaved with ionosonde frequency-sweep mode generating an ionogram every $15 \mathrm{~min}$. The drift was measured using the fixed transmitter frequency mode (Grant et al., 1995).

A polar camera operated in Eureka is a pair of CCDbased all-sky imagers (Steele and Cogger, 1995). The $630.0-\mathrm{nm}$ images to be discussed here are 60-s time exposures at intervals of two to three minutes.

The $48.5-\mathrm{MHz}$ Bistatic Auroral Radar System (BARS) was part of the Canadian Auroral Network for OPEN Unified Study (CANOPUS) ground-based network (Rostoker et al., 1995) before the radars were shut down in summer 1994. The BARS normal mode of operation was described by McNamara et al. (1983), and André et al. (1988). Figure 2 shows the Nipawin and Red Lake radar field-of-view (FoV) projected onto a map that also shows the FoVs of a pair of SuperDARN radars and the CANOPUS sites (referred to later in this work). After the summer of 1992 BARS was operated in a mixed mode. The normal operation mode employed an alternating single-pulse/double-pulse technique to measure the intensity and mean Doppler velocity in $20-\mathrm{km}$ range gates out to a maximum of $1300 \mathrm{~km}$. In every 30 -s time interval, the normal mode 
integrated 450 single pulses for the intensity and 450 double pulses for the mean Doppler determination. The normal mode was interleaved at 5-min intervals with the spectral mode, which was a burst of 34 pulses at a pulse repetition frequency (PRF) of $500 \mathrm{~Hz}$. In the spectral mode the echo ranges were aliased by the $300-\mathrm{km}$ long interval which was established by the $500-\mathrm{Hz}$ PRF. Fourteen of the 15 range gates in each of the eight beams were usable within the $300-\mathrm{km}$ interval and were sampled simultaneously. Normally, the high rate burst analysis used the last 32 pulses as a time series over an interval of 64 milliseconds. Fourier transformations of the 112 simultaneous time series for all range gates yield Doppler spectra with a spectral resolution of approximately $16 \mathrm{~Hz}(50 \mathrm{~m} / \mathrm{s})$. In this mode, spectral aliasing can occur for Doppler shifts greater than $250 \mathrm{~Hz}$ $(773 \mathrm{~m} / \mathrm{s})$. Range and spectral ambiguities can usually be resolved with the aid of the intensity and mean Doppler data from the neighboring 30-s intervals of normal mode operation, for which there are no range ambiguities.

Another CANOPUS instrument group from which data are used in this study is the Magnetometer and Riometer Array (MARIA), whose site coordinates (geographic, geomagnetic and $L$-values) have been listed by Rostoker et al. (1995). Each MARIA site is equipped with a three-component fluxgate magnetometer of the ring-core type and a $30-\mathrm{MHz}$ zenith riometer with an antenna composed of two half-wave dipoles separated by half a wavelength and equipped with a reflector. In the case study presented here (December 2, 1993, 1800 2200 UT) quiet day baselines derived from data on December 9 and 13 are used for magnetometer and riometer data, respectively. Mainly the data from the north-south array (Pinawa (PINA), Island Lake (ISLL), Gillam (GILL), Back (BACK), Fort Churchill (FCHU), Eskimo Point (ESKI) and Rankin Inlet (RANK)) are used in this work, although some data from east-west array are mentioned (Fort Smith (FSMI) and Dawson (DAWS)).

Pure state filtering techniques (Samson and Olson, 1980; Samson, 1983a, b) were used to identify highly polarized Pc5 pulsations and determine their spectral, polarization, and phase characteristics (see Ziesolleck and McDiarmid, 1994).

\section{Dayside event of December 2, 1993: a case study}

On December 2, 1993 (1800-2200 UT), the IMF conditions (Sect. 3.1) were favorable for dayside magnetic merging and polar patch formation. The cusp shifted from $\sim 71^{\circ}$ down to $\sim 68^{\circ}$ magnetic latitude (Sects. 3.2, 3.3 and 3.8). During this disturbed period $\left(K_{p}=7-\right)$, BARS observed a series of poleward-progressing Pc5 backscatter bands entering the cusp from the auroral oval. The bands were associated with discrete riometer absorption enhancements and Pc5 magnetic pulsations (Sects. 3.4 and 3.5) as a result of field line resonances (FLRs) (Sect. 3.6) which occurred near the polar cap boundary (magnetopause) and were correlated with solar-wind-driven, poleward-progressing DPY currents (Sect. 3.3) observed in the cusp and poleward of it. The ground-based data coverage from regions equatorward of the cusp to the central polar cap during this event support evidence in paper 1 that magnetosphere-ionosphere coupling processes on the open and closed field lines are closely interrelated (Sects. $3.4,3.5,3.6$ and 4.2). The F-region irregularities associated with polar patches that formed in, or near, the cusp were observed with SuperDARN (Sect. 3.7). Separate patches, of width 100-200 km, came through the cusp during FCEs (Sect. 3.8) and were observed with CADIs and an all-sky imager as they drifted poleward into and across the polar cap (Sect. 3.9). Combining these multi-instrument observations, we conclude that some of the patches extended over at least $2500 \mathrm{~km}$ in length (Sect. 3.10).

\subsection{Observations of Alfvénic fluctuations in the solar wind}

The IMP 8 spacecraft was located at $(-7.7,-30.3,8.2$ $R_{E}$; GSE coordinates) at 1800 UT and moved to $(-6.4$, $\left.-30.7,7.4 R_{E}\right)$ at 2000 UT. The IMF and plasma measurements were obtained between 1800 and 2050 UT. There were no IMP-8 data available between 2050 and 2315 and several hours before 1800 UT. Figure 3a shows the 15-s interplanetary magnetic field and 1-min plasma parameters (solar wind velocity and proton density). The IMF $B_{z}$ component was negative most of the time ( $-6.7 \mathrm{nT}$ on average). The $B_{y}$ component was positive (4.4 $\mathrm{nT}$ on average) except for a few brief negative excursions. These are favorable conditions for dayside magnetic merging and polar patch formation (Rodger et al., 1994a). The plasma measurements indicate dynamic pressure between 4 and $5 \mathrm{nPa}$. For these solar wind conditions, we have taken the distances of the subsolar magnetopause and bow shock to be about 9 and $12 R_{E}$, respectively (Roelof and Sibeck, 1993; Fairfield, 1971).

The IMF components fluctuated on the scale from a few minutes to an hour and were anticorrelated with corresponding components of the solar wind velocity. The fluctuations of the IMF magnitude and proton density were small. Since the IMF $B_{x}$ was negative (the IMF pointing away from the Sun), on average, the above anticorrelation indicates outward propagating Alfvén waves in the solar wind (Belcher and Davis, 1971). In order to emphasize the short period fluctuations the 1-min IMF and velocity time series were detrended by subtracting the 10-min running average before the pure state filter was applied. Figure $3 \mathrm{~b}$ shows the 3-component pure state filtered time series of the IMF, velocity and the inferred dawn-dusk electric field $(-\boldsymbol{V} \times \boldsymbol{B})$. These time series clearly show Alfvénic fluctuations with periods down to a few minutes. Unfortunately, short period oscillations could not be well resolved because of averaging and interpolation of gaps in the plasma data. The wave Poynting flux $\boldsymbol{S}$ (of the pure state filtered signal; Fig. 3b) further supports the above interpretation of solar wind fluctuations. The 


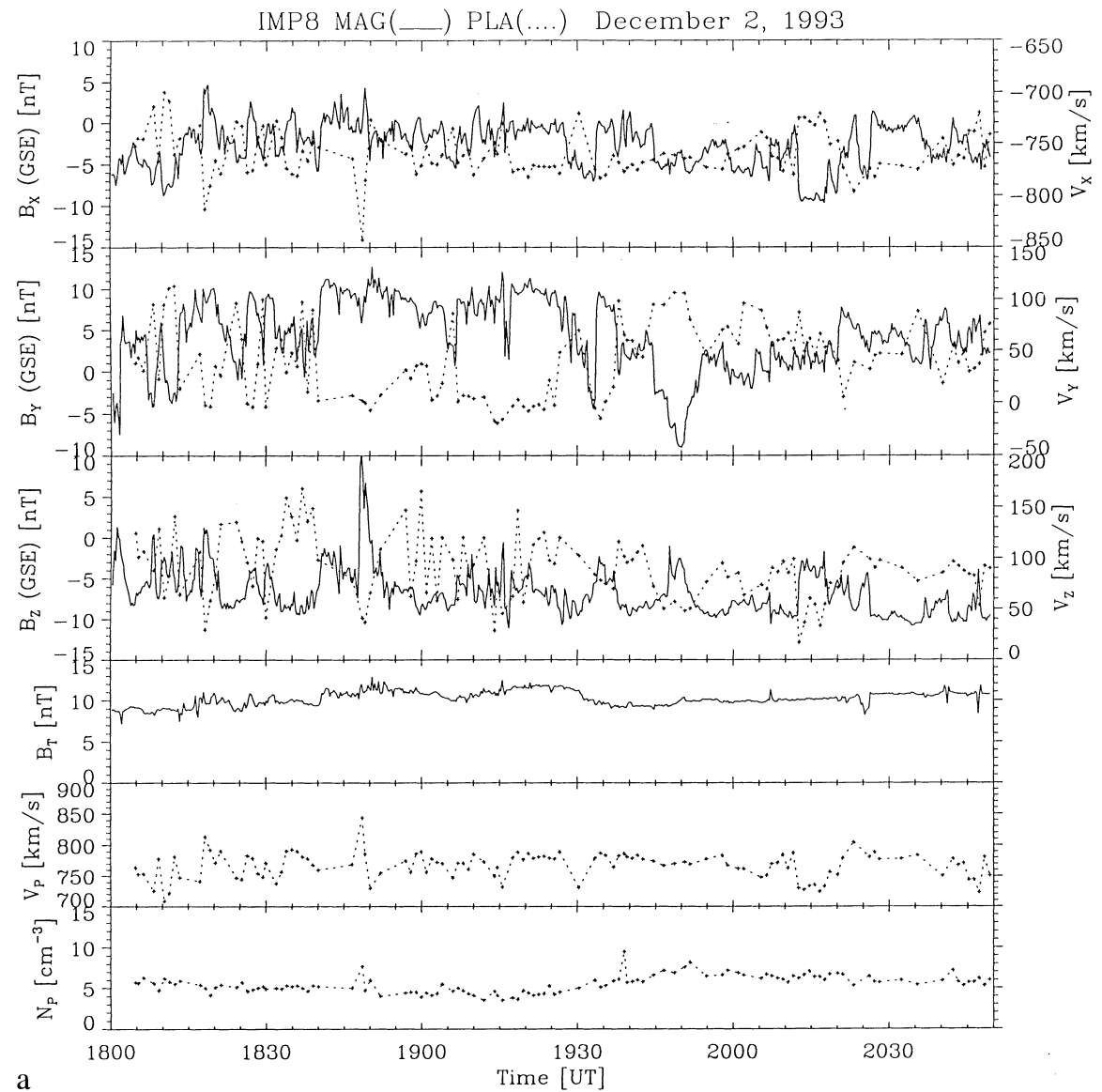

IMP8 December 2, 1993: ELECTRIC/MAGNETIC FIELD AND VELOCITY (Pure States)

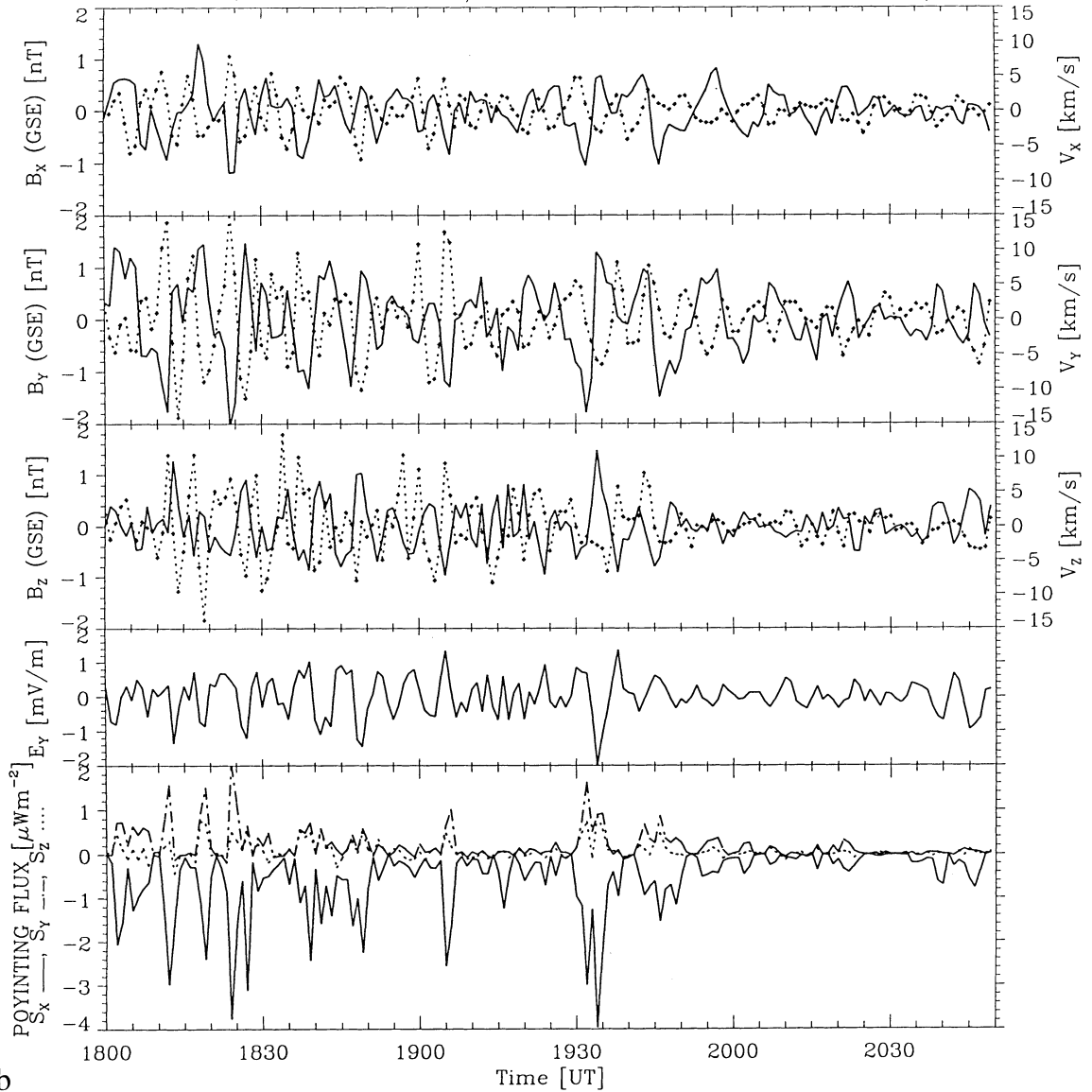

Fig. 3. The IMP-8 15-s interplanetary magnetic field and 1-min plasma measurements demonstrating the presence of Alfvén waves. b The pure state filtered 1-min IMF, solar wind velocity and inferred dawn-dusk electric field. Low frequency oscillations are attenuated by a 10-min detrender. Also, the wave Poynting flux is shown (bottom) 
$S_{x}$-component of the Poynting vector is negative (away from the Sun) and the magnitude is enhanced during two main periods (1800-1850 and 1930-2000 UT). It should be noted that most of the electromagnetic energy was carried by long period Alfvén waves which had larger amplitudes but are strongly attenuated in the time series shown in Fig. 3b. Using the 60-min detrender the peak total Poynting flux exceeded $12 \mu \mathrm{Wm}^{-2}$ as compared to $\sim 4 \mu \mathrm{Wm}^{-2}$ (10-min detrender). The wave electric field was linearly polarized in the plane containing the $X_{G S E}$-axis and inclined at about $45^{\circ}$ to the ecliptic plane - the oscillations of $E_{y}$ and $E_{z}$ (not shown) had similar amplitudes and were anticorrelated. This is favorable for coupling of these Alfvén waves to the subsolar magnetopause. The oscillating dawn-dusk component of the electric field is expected to modulate the magnetic reconnection rate (see, e.g., Lockwood, 1996). In another case study in paper 1, compressional MHD waves in the solar wind were found to modulate the ionospheric cusp flows that were interpreted as signatures of pulsed reconnection at the dayside magnetopause. In the case study presented in this work, the coupling of solar wind Alfvén waves to the dayside magnetosphere is discussed. At times (particularly before 1930 UT), a small admixture of other modes may have resulted in small changes in the magnetic field magnitude, but there was no significant compressional component in the solar wind. However, the interaction between the solar wind Alfven waves and the bow shock can generate both Alfvén waves and dynamic pressure pulses downstream of the bow shock (Lin et al., 1996).

Transmission of Alfvén waves and/or their interaction with the bow shock have been studied by several authors (e.g., McKenzie and Westphal, 1969; Scholer and Belcher, 1971; Hassam, 1978; Sibeck et al., 1997). For the general case of incident Alfvén waves with arbitrary $\boldsymbol{k}$ vectors, this interaction can result in several MHD modes (outgoing waves) that include fast and slow magnetoacoustic modes and Alfvén waves. For a special case, when the incident Alfvén wave $\boldsymbol{k}$ vectors are parallel to, and the field perturbations normal to, the plane $\boldsymbol{B}_{0}-\boldsymbol{n}$ defined by the ambient magnetic field $\boldsymbol{B}_{0}$ and the shock normal $\boldsymbol{n}$, the Alfvén waves are transmitted through the bow shock as forward and backward propagating Alfvén waves (Hassam, 1978). Recently, the observational evidence of this prediction (oppositely propagating Alfvénic fluctuations in the solar wind and magnetosheath) was presented by Sibeck et al. (1997).

For the case study presented we are interested in the interaction and coupling of Alfvén waves near the subsolar points of the bow shock and magnetopause, respectively. The IMP-8 location near the bow shock $\left(Y_{G S E} \approx-30 R_{E}\right)$ and the lack of magnetosheath data precluded any detailed analysis of the Alfvén wave transmission across the bow shock. However, the orientation of the mean IMF (strongly southward) along with the large amplitude of the $B_{y}$ oscillations suggest that the field perturbations were polarized near the plane perpendicular to the $\boldsymbol{B}_{0}-\boldsymbol{n}$ plane (particularly when the ambient IMF had nearly zero duskward component) while the solar wind Alfvén waves propagated along the spiral IMF ( $\boldsymbol{k}$ vectors parallel to the $\boldsymbol{B}_{0}-\boldsymbol{n}$ plane). These geometrical considerations are consistent with the conditions required for transmission of solar wind Alfvén waves to the magnetosheath.

\subsection{The cusp location}

No DMSP satellites passed over the geographical area covered by SuperDARN radars during the time of the event. Later, the poleward edge of the auroral oval in the northern hemisphere was estimated from F11 satellite particle data to be near Fort Churchill at 2207 UT. In the southern hemisphere, the cusp was identified from the particle data (Rich, 1995, private communication) during two passes of the F10 DMSP satellite. It was located at $-69^{\circ}$ magnetic latitude at 1851 and just before 2030 UT. These observations of the particle cusp in the Southern Hemisphere agree (within $2^{\circ}$ of latitude) with the northern radar cusp signatures which extended $1-2^{\circ}$ further equatorward at times.

Baker et al. (1995) showed that, compared to normal spectra, the Doppler spectra of the cusp ionospheric backscatter obtained by HF radars are more complex and have greater spectral widths, which can be used to identify the cusp. Figure 4 (top) shows spectral widths for the Saskatoon radar beam number 7. The large widths $(>250 \mathrm{~m} / \mathrm{s})$ before 1950 UT indicate that the cusp equatorward boundary was located between $68^{\circ}$ and $69^{\circ}$. Just equatorward of the radar cusp is a region identified by lower spectral widths which are typical of the low latitude boundary layer (LLBL) (Baker et al., 1995). Before 1900 UT (not shown), the boundary between large and moderate spectral widths shifted from $\sim 71^{\circ}$ magnetic latitude at $\sim 1730$ UT, when the Saskatoon radar showed a weak cusp signature, down to $\sim 69^{\circ}$ at $\sim 1820 \mathrm{UT}$, when the Kapuskasing radar measured spectral widths of $>200 \mathrm{~m} / \mathrm{s}$ at magnetic latitudes above $69^{\circ}$. Figure 4 shows the radar cusp observed with the Saskatoon radar at $\sim 69^{\circ}$ from 1900 UT. The last clear radar cusp signature was identified with the Kapuskasing radar near $68^{\circ}$ at 2000 UT. At this time, the Saskatoon radar showed large spectral widths at latitudes $>70^{\circ}$ indicating a somewhat fuzzy poleward boundary of the cusp (Baker et al., 1995). It should be noted that "pockets" of enhanced spectral widths can also be observed in the LLBL footprint (Pinnock et al., 1995b), the implication being that large spectral widths are not exclusively associated with the cusp. A band of large spectral widths observed by the Kapuskasing radar in the E-region (at $\sim 500-\mathrm{km}$ range) at 2000 UT (Fig. 4) may or may not be related to the cusp. The widths of the E-region radar spectra are not necessarily an indicator of the cusp because they reflect a different plasma regime and are due to FarleyBuneman/gradient drift instabilities (e.g., Farley and Fejer, 1975) which can result in a variety of spectral shapes including narrow peaks at Doppler velocities ranging from small to very high depending on the 


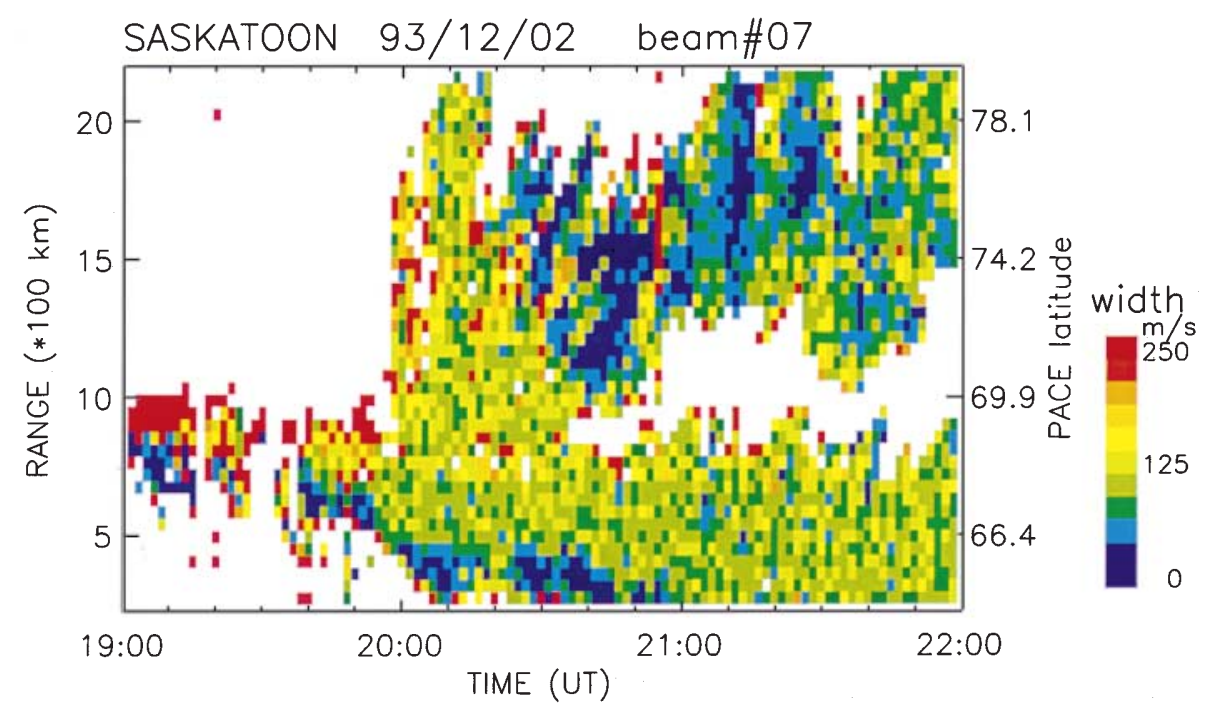

75

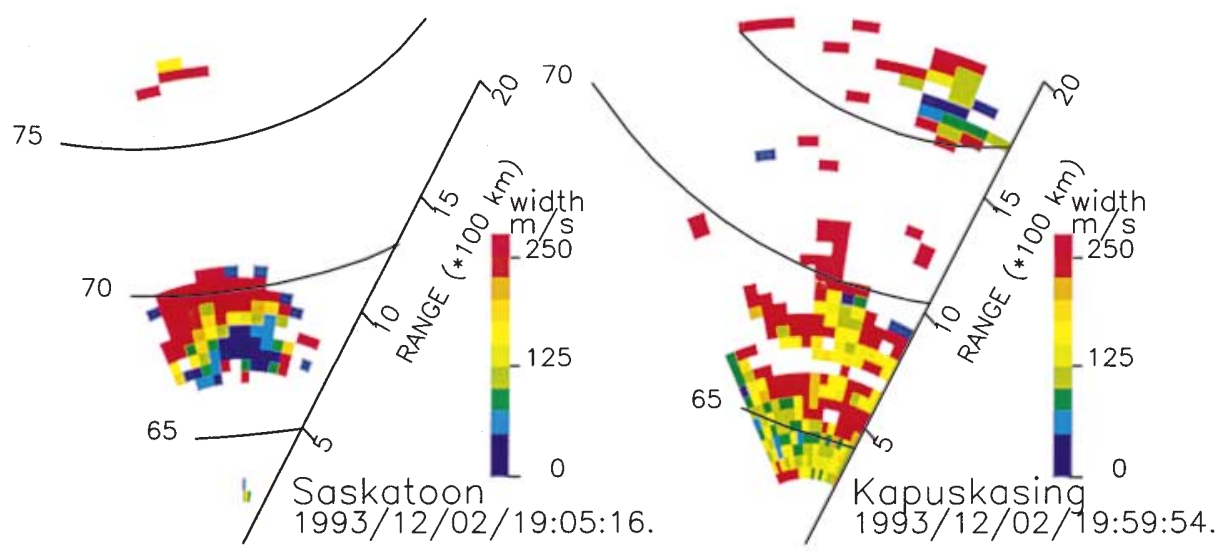

Fig. 4. Range versus time plot (top) and radar maps (bottom) of spectral widths. Radar cusp can be identified by large widths (particularly between 1900 and 2000 UT) while the region of small widths $(<100 \mathrm{~m} / \mathrm{s})$ just equatorward of it can be associated with low latitude boundary layer (LLBL). The spectral widths in the patches drifting antisunward well inside the polar cap are also significantly reduced horizontal density gradient scales and orientations (St.-Maurice et al., 1994; Prikryl et al., 1995). Thus the spatial and temporal averaging of E-region backscatter may result in broad spectra even in the auroral oval. Nevertheless, it was observed that the region of very narrow widths (Fig. 4) kept shifting equatorward. This and the fact that FCEs were observed at progressively lower latitudes (Sect. 3.8) indicate that the cusp also shifted further equatorward as more and more closed magnetic flux was eroded by flux transfer events after 2000 UT. The polar cap expanded as far equatorward as $70^{\circ}$ magnetic latitude at 2045 UT as indicated by significantly reduced spectral widths associated with patches (Fig. 4). The equatorward shift of the cusp also agreed with observations of DPY currents associated with the FCEs discussed later. Also, it should be noted that the cusp can span up to $6 \mathrm{~h}$ of local time (Crooker et al., 1991; Newell and Meng, 1994). At 2100 UT, most of the radar data are from magnetic local times before 1400 MLT and the Northern Hemisphere cusp is expected to be shifted into the afternoon sector for the IMF $B_{y}>0$ (Cowley et al., 1991). This supports the argument that the cusp/cleft was present and observed by the radars at near ranges until at least 2200 UT $(\sim 1500$ MLT).

\subsection{Poleward edge of the ionospheric cleft currents (DPY currents)}

Figure 5 shows 5 -s ground magnetic $X$-component (quiet time mean value subtracted) from the CANOPUS meridional chain and the 30-s IMF $B_{y}$-component (broken line; solid line shows the smoothed trace). During the first hour shown (1700-1800 UT), poleward-progressing currents were observed poleward of FCHU. At $\sim 1730 \mathrm{UT}$, as we mentioned already, the Saskatoon radar showed a weak signature of a radar cusp with an equatorward boundary at $\sim 71^{\circ}$ magnetic latitude. After 1800 UT, the poleward-progressing disturbances were correlated with the IMF $B_{y}$-component and thus were due to eastward DPY (Hall) currents (Friis-Christensen and Wilhjelm, 1975; Clauer et al., 1995; Stauning et al., 1995) poleward of, and near, the cusp that now shifted further equatorward. The thick arrows in Fig. 5 show corresponding phases 


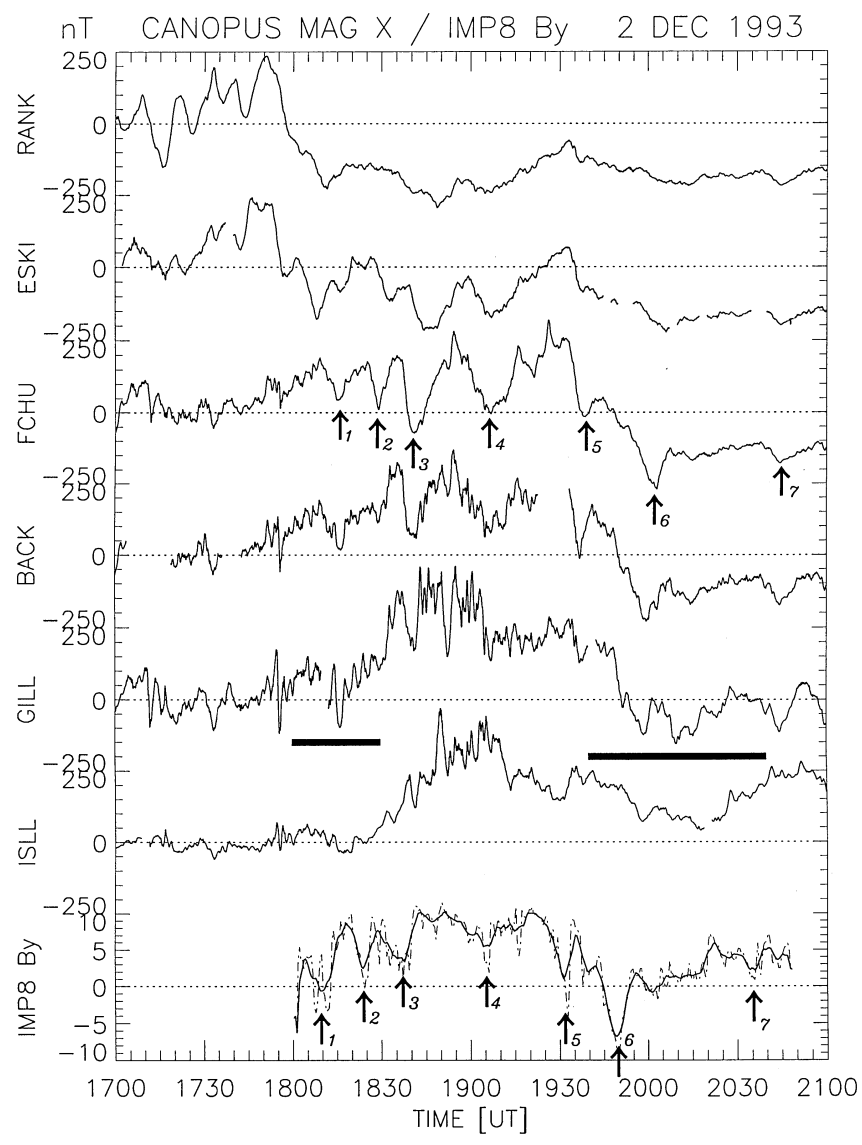

Fig. 5. The $X$-component ground magnetic perturbations measured by the CANOPUS north-south magnetometer array. The bottom trace is the smoothed (solid) and unsmoothed (broken) IMP-8 30-s IMF $B_{y}$ component. The arrows indicate corresponding phases of long-period variations of IMF $B_{y}$ component and poleward-progressing magnetic disturbances (DPY currents). The horizontal bars indicate two pulsation periods discussed in the text

of the long-period variations of the IMF $B_{y^{-}}$and ground $X$-components. A major equatorward shift of the poleward boundary of the DPY current system is noted at 1755 UT (from RANK to ESKI) followed by a further equatorward expansion $(\sim 1840$ UT) to FCHU. This boundary briefly recovered back to ESKI at 1920 UT but then suddenly expanded equatorward again at 1935 UT through FCHU and BACK to GILL and later shifted even further south towards ISLL. This was confirmed by obtaining the latitude profiles of magnetic perturbation that can be used to estimate the three-dimensional current system (Hughes and Rostoker, 1977). The position of the poleward edge of the eastward DPY current system is determined by the location of the negative extremum of the $\mathrm{Z}$ component approximating the position of the polar cap boundary which is shown in Fig. 6b. Mapped along the westernmost beam number 1 of the Nipawin radar it approximately matched the poleward edge of the BARS backscatter (Fig. 6a). This boundary and the boundary between large and small spectral widths observed by the SuperDARN radars approximately bracketed the cusp but most likely included parts of the LLBL ionospheric footprint (see Sect. 3.2).

\subsection{The correlation between the IMP-8 IMF $B_{y}$ and the ground and ionospheric data}

It is well known that the IMF $B_{y}$ component controls the dayside cleft current system (Banks et al., 1984) and plays an important role in the dayside magnetic reconnection (Crooker, 1979; Cowley et al., 1991; Taguchi et al., 1993; Newell et al., 1995). A number of studies have clearly demonstrated the solar-wind-driven modulation of the dayside ionospheric DPY currents and convection on the open field lines (Clauer et al., 1984; Clauer and Banks, 1986; Greenwald et al., 1990; Clauer et al., 1995; Stauning et al., 1995). The results presented here show that the IMF has also a strong influence on the ionosphere at the footprint of the closed field lines near the magnetopause where the FLRs can be driven by oscillations in the solar wind IMF (see discussion of Figs. 6a and 8).

Figure 6 a shows the 30 -s IMF $B_{y}$ time series shifted by $7 \mathrm{~min}$ superposed on the BARS Nipawin radar range-time-intensity (RTI) plot. This time shift results in a very good correlation between the IMF $B_{y}$ and the poleward edge of the backscatter intensity. At the bottom of Fig. 6a, the pure state filtered dawn-dusk solar wind electric field $E_{y}$ (shown unshifted), which was also correlated with the poleward progressing backscatter bands (discussed in Sect. 3.5). We now concentrate on the correlations with the IMF $B_{y}$. Cross-correlation functions (CCFs) for time series of the IMF $B_{y}$ and the Nipawin radar backscatter power (beam 1) were computed for each range gate with significant backscatter using eleven 30-min windows with the centers of the adjacent windows separated by $15 \mathrm{~min}$ (overlapping by $15 \mathrm{~min}$ ). The "zero lag" vertical lines in Fig. 6c are labeled with the start times of the successive windows. The ground magnetic $X$ component and the IMF $B_{y}$ were detrended by subtracting a polynomial fit and the IMF $B_{y}$ was smoothed using a 5 -min window for BACK, FCHU, ESKI and RANK for reasons that were discussed by Stauning et al. (1995) who presented a similar cross-correlation analysis of DPY currents. However, no smoothing was applied to $B_{y}$ time series when cross-correlations were computed for GILL and ISLL where the higher frequency pulsations were strong and correlated with the IMF $B_{y}$ component. Figure 6c shows that, in general, the backscatter power associated with the poleward-progressing bands was correlated with the IMF $B_{y}$ oscillations (correlation coefficients often $>0.5$ ). Note that the correlation was poor for the strong backscatter signals between 1830 and 1900 UT at ranges from 400 to $700 \mathrm{~km}$ which were associated with bands moving equatorward rather than poleward. Because this backscatter feature is quite distinct from the poleward-progressing bands and the backscatter is contaminated by aliasing we choose to ignore it in the discussion. The time lags (CCF maxima) with significant correlation (coefficients often $>0.5$ ) that are plotted for 


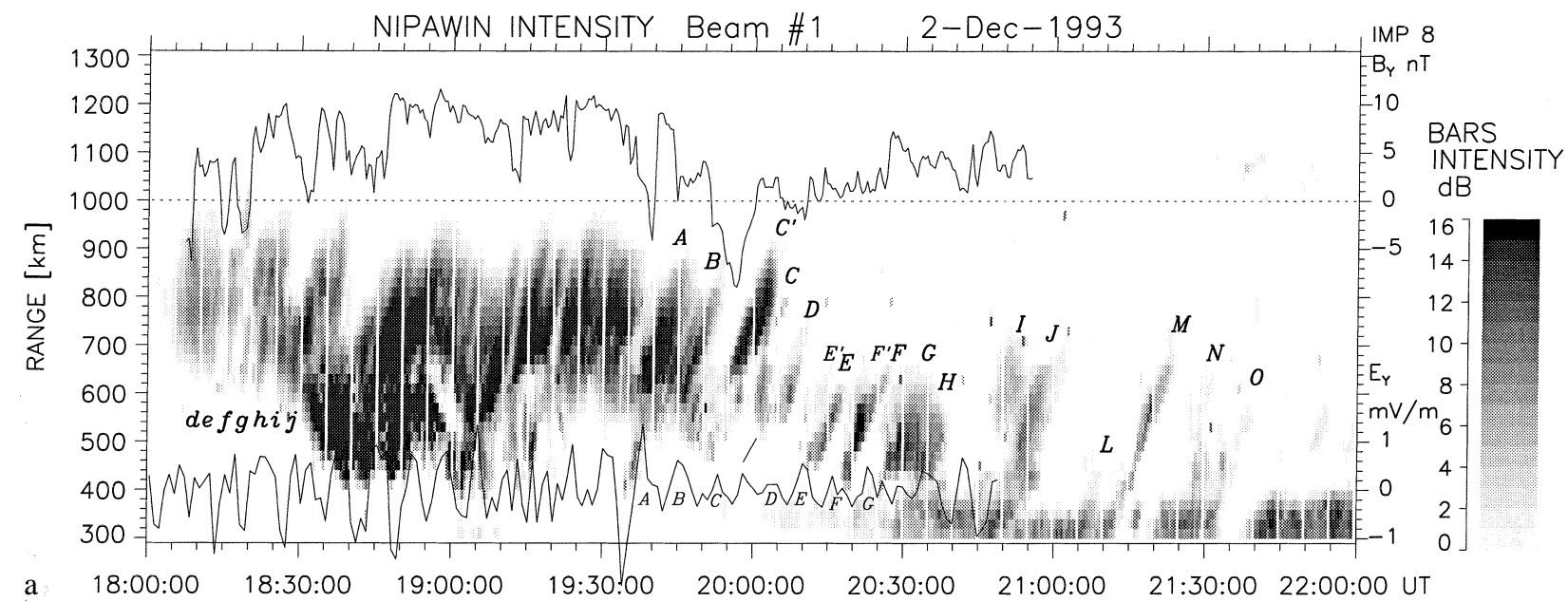

CANOPUS: POLEWARD EDGE OF DPY CURRENTS (

SuperDARN: EQUATORWARD EDGE OF LARGE SPECTRAL WIDTH(....)
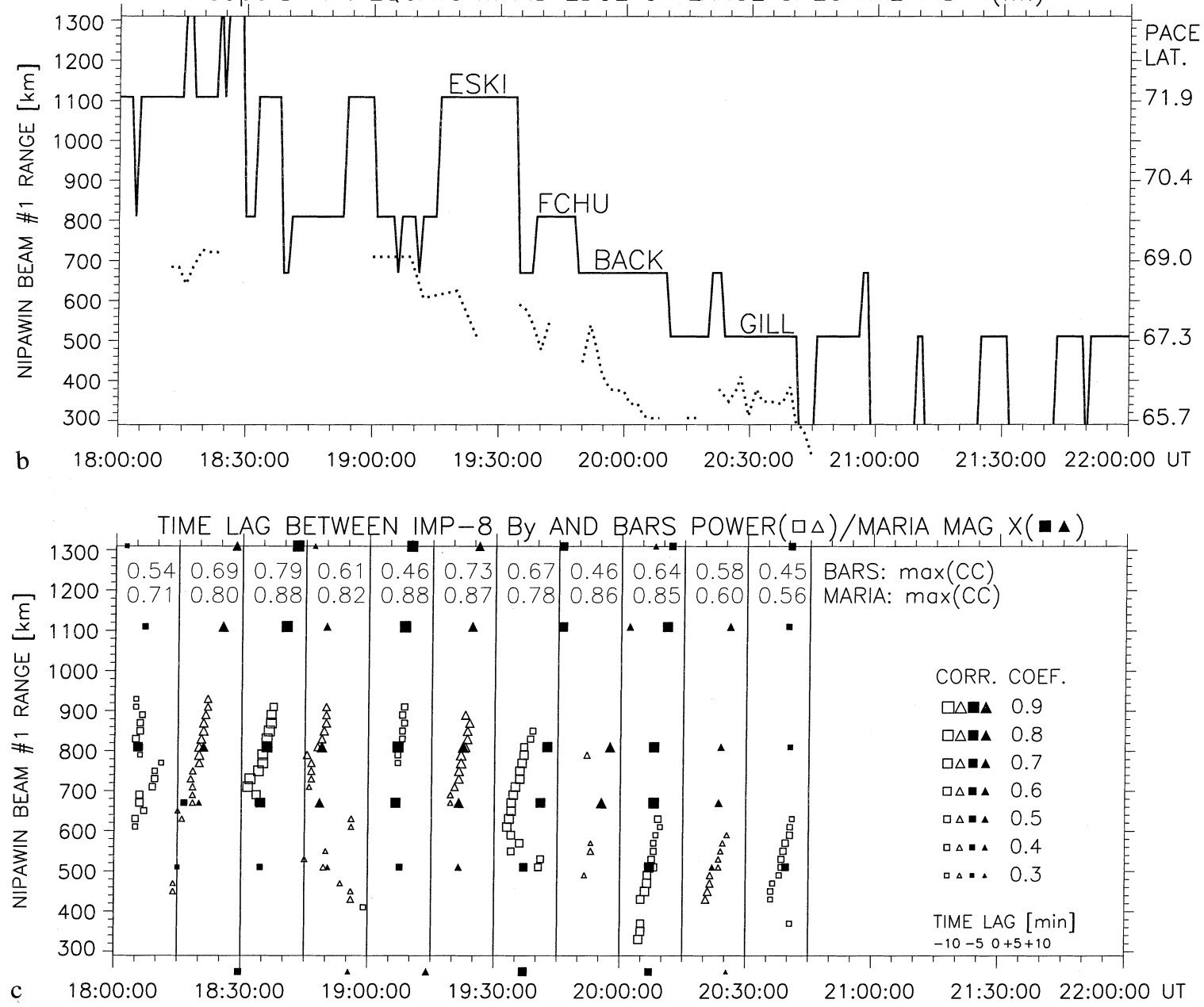

Fig. 6. a Range-versus-time plot of the Nipawin radar backscatter power. The poleward-progressing Pc5 FLR bands for two events are labeled. The IMP-8 IMF $B_{y}$ component (top) shifted by $7 \mathrm{~min}$ and the pure state filtered dawn-dusk electric field $E_{y}$ (unshifted at the bottom) are shown. b An approximate position of the poleward edge of the eastward DPY (Hall) currents and the equatorward boundary of large spectral widths measured by SuperDARN radars are mapped along the Nipawin radar beam 1 (leftmost beam). $\mathbf{c}$ Time delays between the IMF $B_{y}$ component and the ionospheric/ground signals obtained from CCFs computed for 30-min windows stepped by $15 \mathrm{~min}$ are

plotted. The vertical lines represent the zero delays and/or the start time for the corresponding window. The delays for the BARS power (open symbols) and CANOPUS magnetometer $X$ components (solid symbols) are plotted for correlation coefficients greater than 0.3 . The largest values of the cross-correlation coefficient for BARS (first row) and MARIA (second row) are printed at the top for each window. The first set of points (squares) is for the interval of 1800-1830 UT, the second set of points (triangles) is for the interval of 1815-1845 UT, etc. A generic scale for time lags is shown (bottom-right) 
each 30-min window in Fig. 6c increased with range/ latitude from a few minutes (at the low-latitude edge of the backscatter where the E-region bands started to appear) up to several minutes near the polar cap boundary or cusp (Fig. 6b). These radar results are in good agreement with those for the magnetometer data. Time delays obtained from CCFs for IMF $B_{y}$-/ground $X$-component data sets that were highly correlated are also shown in Fig. 6c. The largest values of the crosscorrelation coefficient are printed for each window for BARS (first line of numbers at the top) and MARIA (second line). The time lags obtained for the radar backscatter power and ground magnetic perturbations disagreed in the 30-min window starting at 1930 UT when the IMF $B_{y}$ oscillated between positive and negative values thus reversing the polarity of DPY currents.

These results are similar to the observations of poleward-progressing $B_{y}$-related ionospheric disturbances (Stauning et al., 1995). The latter authors closely examined the observed time delays and found good agreement with the values they calculated. IMP 8 was located somewhat unfavorably during the event presented here. However, the conditions in the solar wind (the IMF orientation and dynamic pressure of 4-5 nPa) were very similar to those for the event of August 2, 1981 (Stauning et al., 1995) and gave similar distances for the subsolar bow shock and magnetopause (Sect. 3.1). With the spacecraft at $\sim 7 R_{E}$ downstream from the Earth and solar wind speed of $770 \mathrm{~km} / \mathrm{s}$, negative propagation delays of about -2.5 min between IMP 8 and the bow shock subsolar point are expected. The propagation time of the decelerated solar wind from the bow shock to the magnetopause could exceed $2 \mathrm{~min}$ (e.g., Clauer and Banks, 1986, derived $4 \mathrm{~min}$ ) and thus would likely eliminate the negative propagation delay between IMP 8 and the bow shock. So the measured delays (shown in Fig. 6c) and those inferred from pure state filtered time series (Fig. 8; discussed later) approximately represent the propagation times in the magnetosphere across and/or along the field lines. For BARS data, at times, the minimum time lags of the IMF $B_{y^{-}}$ driven ionospheric disturbances were 1-2 min near the equatorward edge of the backscatter region. This short delay could result if the disturbances propagated in fast mode before coupling to the shear mode at smaller $L$ shells. The measured delays are significantly smaller (by $\sim 10 \mathrm{~min}$ for cusp locations) than those obtained by Stauning et al. (1995), who mainly discussed the dayside convection disturbances observed poleward of the cusp. Our results show that these solar-wind-driven disturbances spanned both the regions poleward and equatorward of the cusp and that the coupling processes on the open and closed field lines are closely interrelated (as discussed in paper 1).

\subsection{Solar wind Alfvén wave driven Pc5 pulsations near the cusp footprint}

The Pc5 pulsations that were observed with radars, magnetometers and riometers clearly spanned the re- gions of closed and open field lines. We shall concentrate on two periods (1800-1830 UT and 1940-2040 UT; hereafter referred to as event 1 and event 2, respectively) when the pulsations appeared to be most coherent and the BARS data were the least contaminated with sidelobe leakage due to very intense backscatter.

Associated with the sudden expansion of the polar cap at $\sim 1755$ UT the CANOPUS magnetometers (ISLL, GILL, BACK, and FCHU) observed a strong burst of a linearly polarized oscillation in the northsouth direction (Fig. 5) with frequency of $\sim 5 \mathrm{mHz}$ (3$4 \mathrm{~min}$ ). This oscillation, which was also observed with riometers (Fig. 7), was the strongest around the magnetic shell $L \sim 7$ (GILL/BACK) and initially had a nearly zero azimuthal wave number. Virtually no phase shift either in latitude or longitude could be measured before 1800 UT during this initial burst of the pulsation (centered at $\sim 1755$ UT; Fig. 5 and 7 ) that maximized further westward at FSMI (not shown) where the amplitude of the oscillation in absorption was $\sim 2 \mathrm{~dB}$. Weak backscatter was observed with the Red Lake radar during this earlier time.

After $1800 \mathrm{UT}$, the BARS radars and riometers observed poleward drifting backscatter/absorption bands $a-j$ between GILL and FCHU (Figs. 6a and 8). The Nipawin radar power was correlated with the IMF $B_{y}$ that showed short period (3-4 min) oscillations superposed on a long period ( $\sim 15 \mathrm{~min})$ fluctuation. The IMF- $B_{y}$ fluctuations lead those of the Nipawin radar power by $\sim 5 \mathrm{~min}$ on average (Fig. $6 \mathrm{a}, \mathrm{c}$ ). Figure $8 \mathrm{~d}$ shows pure state filtered riometer time series (4 stations) that are compared with 3-component pure state filtered IMF (only $B_{y}$ and $B_{z}$ components are shown and shifted by $4.5 \mathrm{~min}$ ). To attenuate the low frequency oscillations all time series were detrended by subtracting the 5-min running average before applying the pure state filter. The riometer absorption fluctuations are correlated with the IMF $B_{y}$ and show similar 3-4 min oscillations (the maximum correlation coefficients and corresponding time lags are shown). Similar oscillations are also resolved in pure state filtered magnetometer data $(X$ components measured at GILL, ISLL and PINA are shown in Fig. 8a). There is a clear correspondence

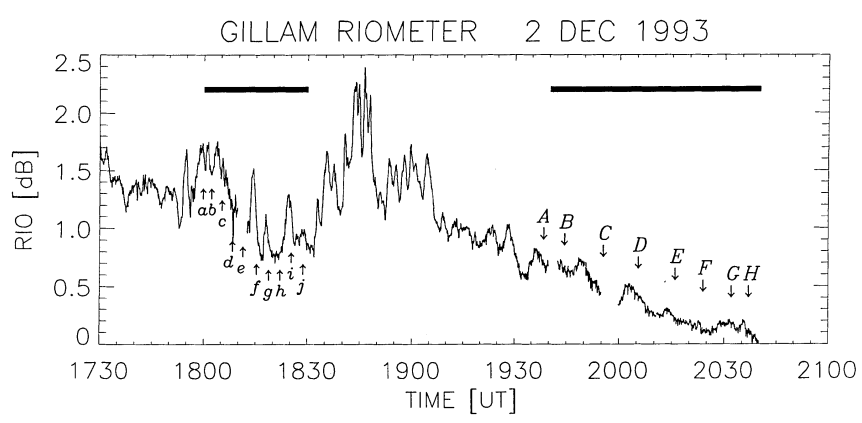

Fig. 7. The riometer absorption at Gillam. The horizontal bars indicate two pulsation periods discussed in the text. The arrows indicate the times of the overhead passages of the BARS backscatter bands trailing the absorption enhancements as they drifted poleward over Gillam 


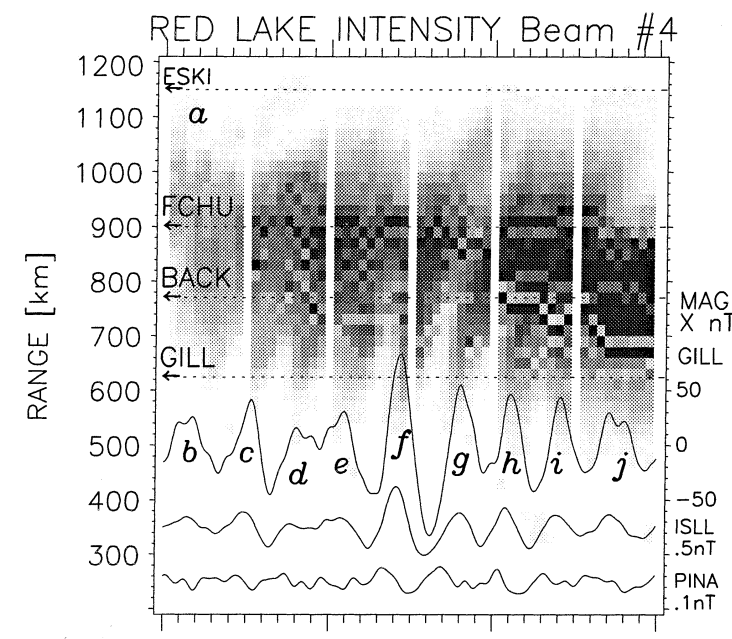

a 18:00:00 18:10:00 18:20:00 18:30:00UT

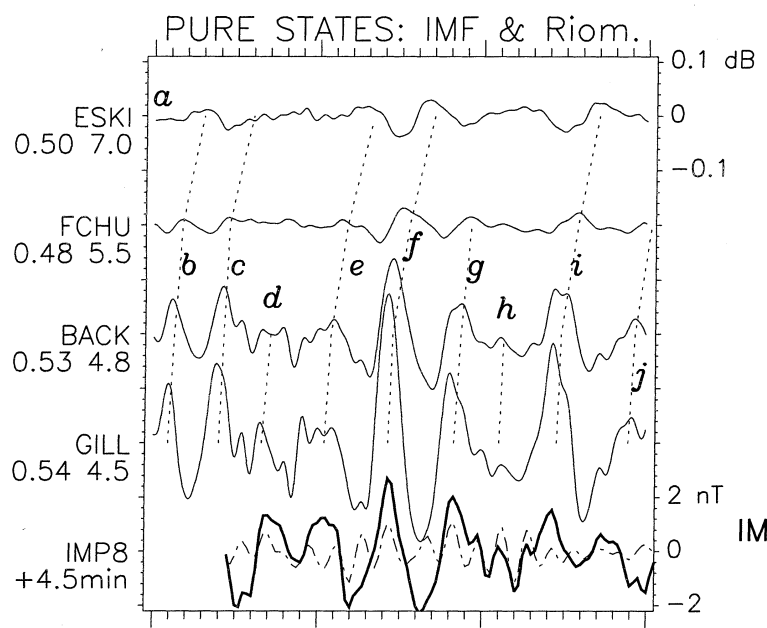

d 18:00:00 18:10:00 18:20:00 18:30:00UT

Fig. 8. a The Red Lake radar backscatter power. Poleward drifting backscatter bands $a-i$ are correlated with the pure state filtered ground magnetic pulsations indicating FLRs. The strongest radar backscatter is side-lobe contaminated. Horizontal dotted lines show mapped positions of four CANOPUS stations. b The Nipawin radar backscatter power. The FCHU and BACK riometer absorption (detrended) time series are superposed. c The Nipawin radar Doppler

between the IMF $B_{y}$, ground magnetic oscillations, riometer absorptions and the VHF radar backscatter power. Similarly to the radar backscatter bands, the riometer absorptions progressed poleward with the oscillations at GILL leading those at ESKI in phase by about $180^{\circ}$. The phase of the magnetic pulsation progressed poleward from PINA to GILL but then stayed nearly constant for BACK and FCHU (not shown) while the oscillation amplitude peaked at GILL. The amplitude of the riometer absorption oscillation tapered off from GILL to ESKI, while the BARS bakscatter power peaked between BACK and FCHU. It should be noted that the radar backscatter power is highly aspect sensitive (line-of-sight magnetic field aspect angles decreased with the range for both radars and were $\sim 5^{\circ}$ and $3^{\circ}$ at $800 \mathrm{~km}$ for Nipawin and Red Lake radars, respectively). If the discrete absorptions

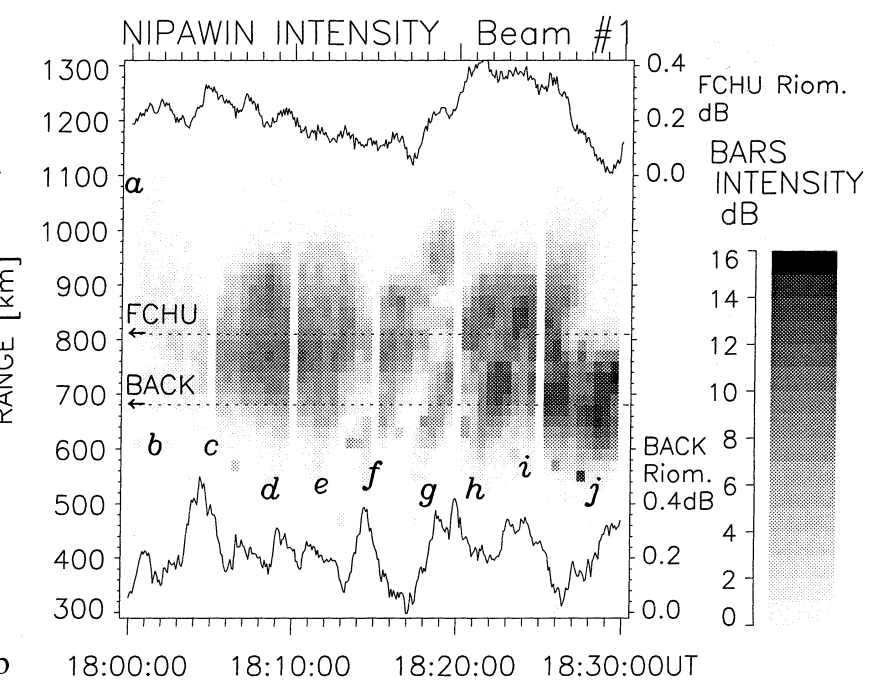

b $\quad 18: 00: 00 \quad 18: 10: 00 \quad 18: 20: 00 \quad 18: 30: 00 U T$

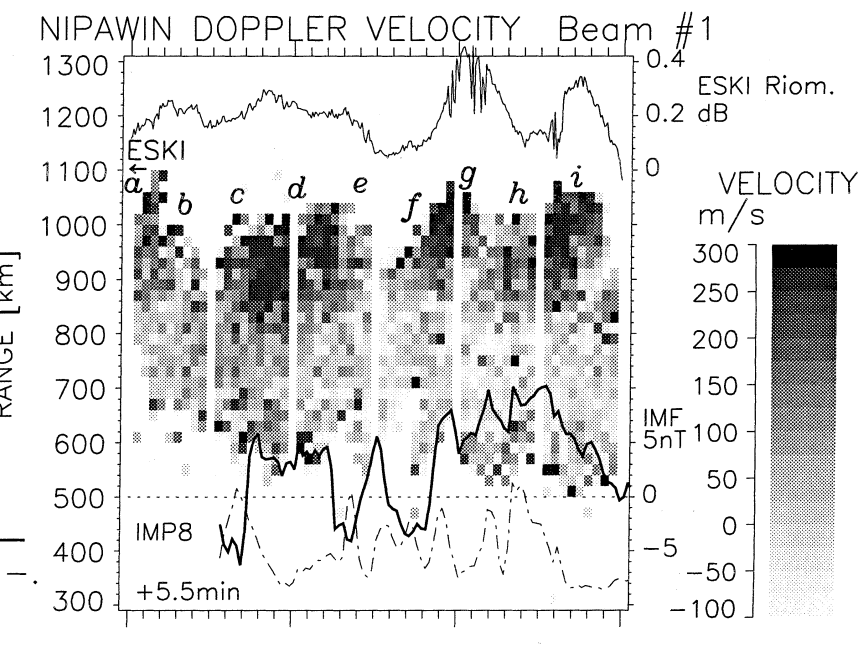

c $\quad 18: 00: 00 \quad 18: 10: 00 \quad 18: 20: 00 \quad 18: 30: 00 U T$

velocity. The ESKI riometer absorption (detrended) and IMP-8 IMF $B_{y}$ (shifted) are superposed. The flow bursts near the cusp are associated with riometer absorption and flow channel events observed with SuperDARN in the cusp. $\mathbf{d}$ Pure state filtered riometer and IMF $B_{y}$ and $B_{z}$ (shifted). The maximum correlation coefficients for the riometer absorption and IMF $B_{y}$, and corresponding lag times are shown

were associated with auroral arcs, refraction of VHF radio waves would bring the beam close to perpendicularity with the magnetic field about $50-150 \mathrm{~km}$ behind the arc where the backscatter power would maximize (Watermann, 1990; Hall et al., 1990; Prikryl and Cogger, 1992). This is about the distance between GILL and BACK and could explain the separation between the peak in the backscatter power and the peak in the amplitude of riometer absorption and ground magnetic oscillations. It is less clear why the phase of the magnetic pulsation did not continue to decrease (progress) poleward of GILL while it did so for the riometer and radar data. However, the large amplitude of the pulsation observed in GILL suggests intense ionospheric currents which could have been strong enough to dominate the magnetic perturbation at BACK/FCHU and mask weaker ionospheric currents 
flowing immediately above these stations. Apart from the latter anomaly, the above magnetometer, riometer and radar observations are consistent with poleward drifting auroral arcs associated with FLRs (see also Sect. 3.6).

The pulsations continued after 1830 UT but were more complex (composed of several oscillation frequencies superposed) while the IMF $B_{y}$ remained strongly positive $\left(B_{y} \approx+10 \mathrm{nT}\right)$ and $B_{z}$ was southward except for a brief turning to northward at $\sim 1848$ UT. The GILL riometer absorption (Fig. 7) and the BARS backscatter power (Fig. 6a) increased significantly while fluctuating with short periodicities but were more irregular than before 1830 UT. These observations indicate intense precipitation which was apparently a result of strong coupling of the solar wind wave energy to the magnetopause (note a $\sim 7$-min oscillation of the IMF $B_{z}$ and corresponding oscillation of the inferred dawn-dusk electric field $E_{y}$ ). This precipitation likely resulted in a dense ionosphere which precluded SuperDARN observations for about an hour due to HF absorption.
The second major equatorward shift of the eastward current system at 1935 UT (Figs. 5, 6b) occurred when the IMF $B_{y}$ component sharply turned negative and then quasiperiodically oscillated about zero (Figs. 3a or 6a). These oscillations were associated with Pc5 pulsation (event 2) observed in the ionosphere and on the ground (Figs. 5, 6a, and 7). BARS observed a series of poleward-progressing backscatter bands (labeled $A-O$ in Fig. 5a). Figure 9 shows an example of BARS maps of the backscatter power and line-of-sight (LOS) velocities for the Red Lake radar. Note that some backscatter bands occurred in pairs with a narrow gap between them. Also, the two bands had opposite Doppler shifts (see, e.g., bands $E^{\prime}$ and $E$ in Fig. 9). The most reasonable explanation is that an optical arc was located in the gap, and that oppositely directed electric fields pointed into the arc from the north and south sides. The backscatter was associated with the gradients and electric fields at the edges of the arc. Similarly to event 1 the backscatter bands $A-H$ (event 2) were closely
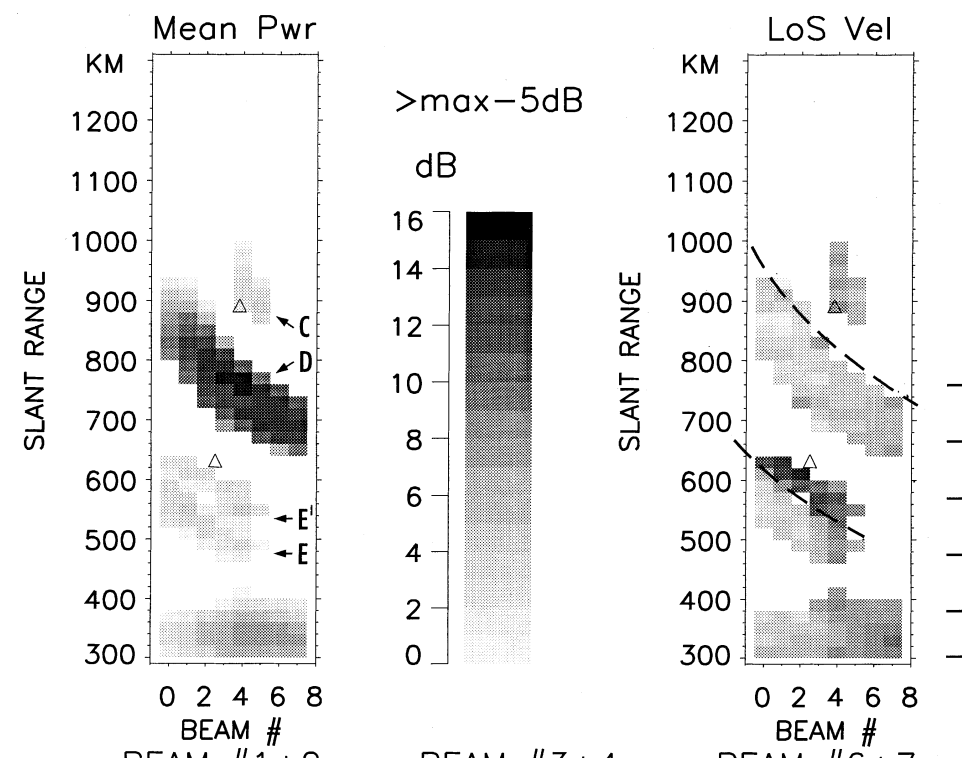

$02-12-93$
20:09:30UT
BARS MODE 4

$$
\mathrm{m} / \mathrm{s}
$$
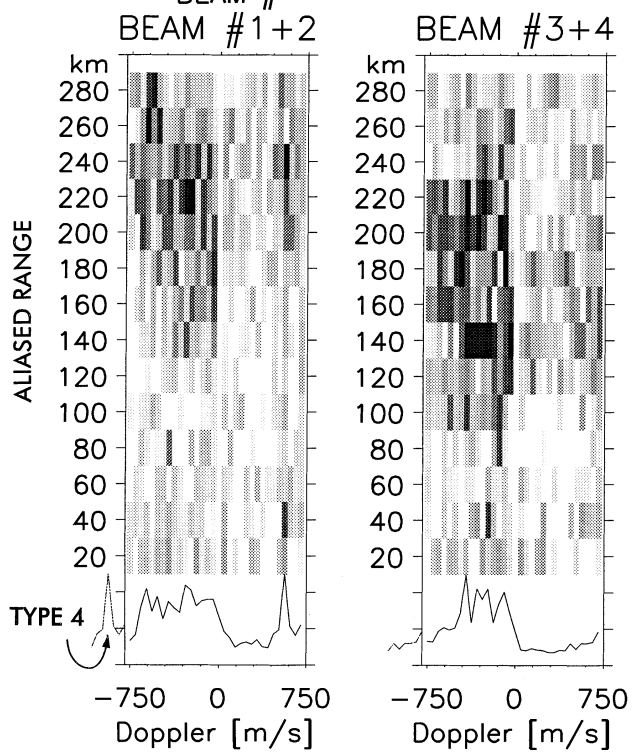
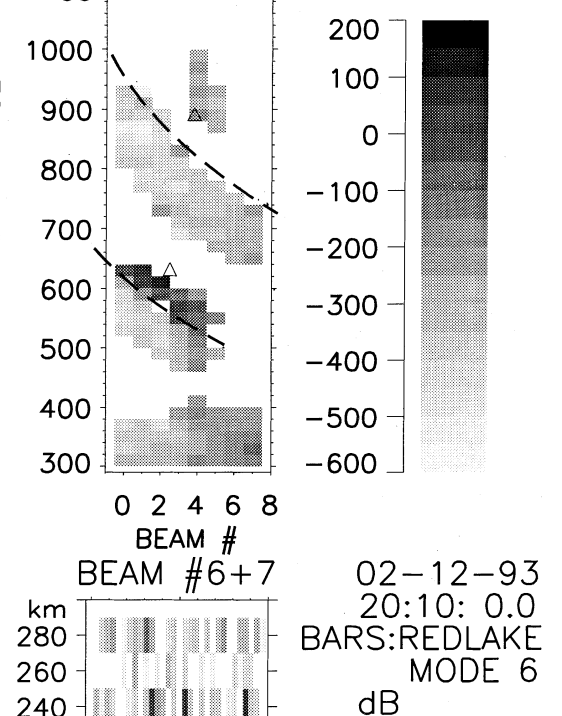

$240-$ III I III |- $\mathrm{dB}$

220

200

180

160

140

120

100
80

60

40
20

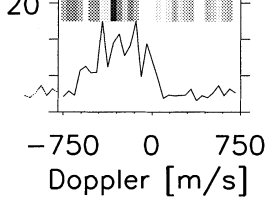

Fig. 9. BARS Red Lake radar maps of the mean backscatter power and line-ofsight velocities for the Red Lake (top panels). Location of GILL and FCHU CANOPUS sites are shown and the individual bands are labeled. Broken lines represent likely positions of auroral arcs indicated by riometer absorption observed when the structures moved overhead in GILL. BARS spectra (bottom panels; add $600 \mathrm{~km}$ to the aliased range to obtain the true slant range) near the cusp (band $D$ ). Both the frequency and range aliasing can be resolved by examining the mean power and Doppler obtained $30 \mathrm{~s}$ earlier (top panels) 
associated with riometer absorption (backscatter trailing the absorption enhancements at GILL; see Fig. 7) suggesting that the backscatter was located near the equatorward edge of an arc. However, at this time the cusp/cleft shifted further equatorward and there were no riometer data available south of GILL. (There were no riometer data from ISLL, a gap in the riometer data from BACK, and no optical data available at auroral latitudes during this daytime event.) BARS spectral mode (Fig. 9; bottom panels) showed broad and complex spectra as these "arcs" entered the cusp/cleft region. The spectra are averaged for two adjacent beams and also for all ranges. The latter average is shown in the line plot at the bottom. An aliased (in range and frequency) type-4 peak $(-900 \mathrm{~m} / \mathrm{s})$ is superposed on a broad component. The range aliasing can be resolved because the spectra are clearly associated with the strongest backscatter band $D$ (for the true range $600 \mathrm{~km}$ should be added to the aliased range shown in Fig. 9). Also, the frequency aliasing can be resolved because the mean Doppler velocity was highly negative during the standard mode of BARS operation $30 \mathrm{~s}$ earlier (Fig. 9; top panels), clearly indicating that the peak near $+600 \mathrm{~m} / \mathrm{s}$ must be aliased as shown (Fig. 9; bottom left). Such spectra are explained by strong electric fields, electron heating, and/or steep horizontal gradients in the electron density associated with auroral arcs (St.-Maurice et al., 1994; Prikryl et al., 1995). Previously, large BARS and optical databases were examined and it was found that backscatter bands such as those shown in Fig. 9 are commonly associated with auroral arcs (Prikryl and Cogger, 1992).

Similarly to event 1 the backscatter bands and associated riometer absorptions at GILL strongly sug- gest poleward moving auroral forms and FLRs which are discussed later. As we have already discussed in Sect. 3.4, the IMF $B_{y}$ is well correlated with the radar, magnetic and riometer pulsations. The pure state filtered dawn-dusk electric field $E_{y}$ (Fig. 3b) of the Alfvénic fluctuations in the solar wind is also shown in Fig. 6a. After $1930 \mathrm{UT}$, the $E_{y}$ oscillation with a period of 6-8 $\mathrm{min}$ is closely correlated with the VHF radar backscatter power (event 2). There is one-to-one correspondence between the duskward turnings of the wave electric field and the poleward-progressing backscatter bands.

For SuperDARN, at ranges less than $800 \mathrm{~km}$, the limited refraction usually limits observations to E-region irregularities. Similarly to BARS, SuperDARN observed the poleward drifting Pc5 bands, although with lower spatial and temporal resolution. There was considerably less SuperDARN E-region backscatter before 2000 UT, when the Kapuskasing radar (Fig. 10a) observed only a trace of several Pc5 bands. After 2000 UT, a direct comparison between BARS and SuperDARN was possible for the Nipawin radar beam 1 (Fig. 6a) and the Saskatoon SuperDARN beam 12 (Fig. 10b). These RTI plots showed a good correspondence between the E-region backscatter bands observed with both radars. The spatial correlation of the VHF and HF backscatter is further discussed in Sect. 3.7 and 3.8 .

We have already mentioned several oscillation modes that were identified in the solar wind and ground/ ionospheric data. Figure 11a, b shows normalized MEM power spectra of pure state filtered solar wind magnetic and inferred electric fields, riometer absorption, BARS backscatter power and ground magnetic pulsations for events 1 and 2. Low resolution FFT

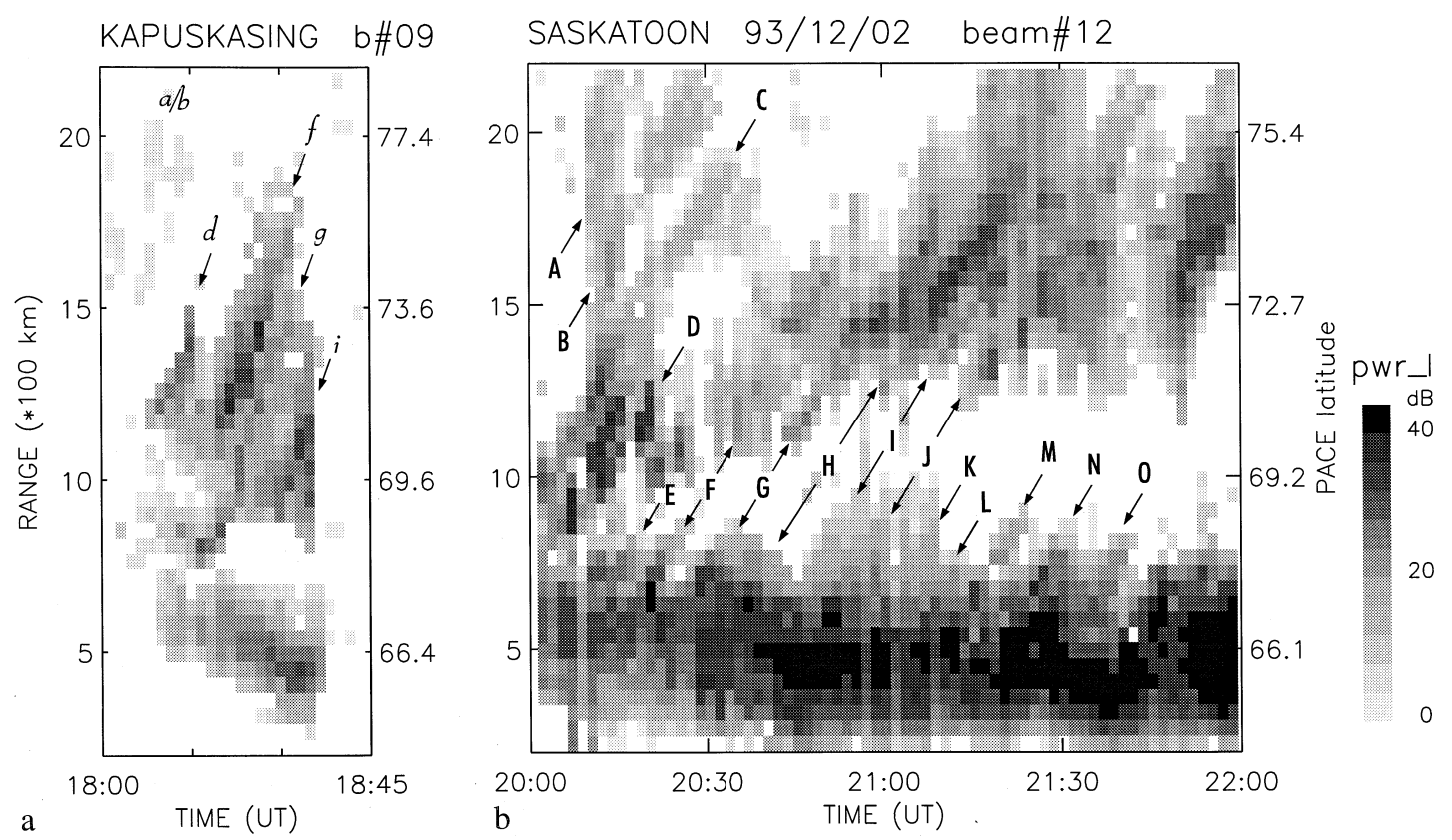

Fig. 10a, b. SuperDARN RTI plots for a Kapuskasing and b Saskatoon radars before and after 2000 UT, respectively. The E-region backscatter bands and corresponding F-region patches are labeled. 

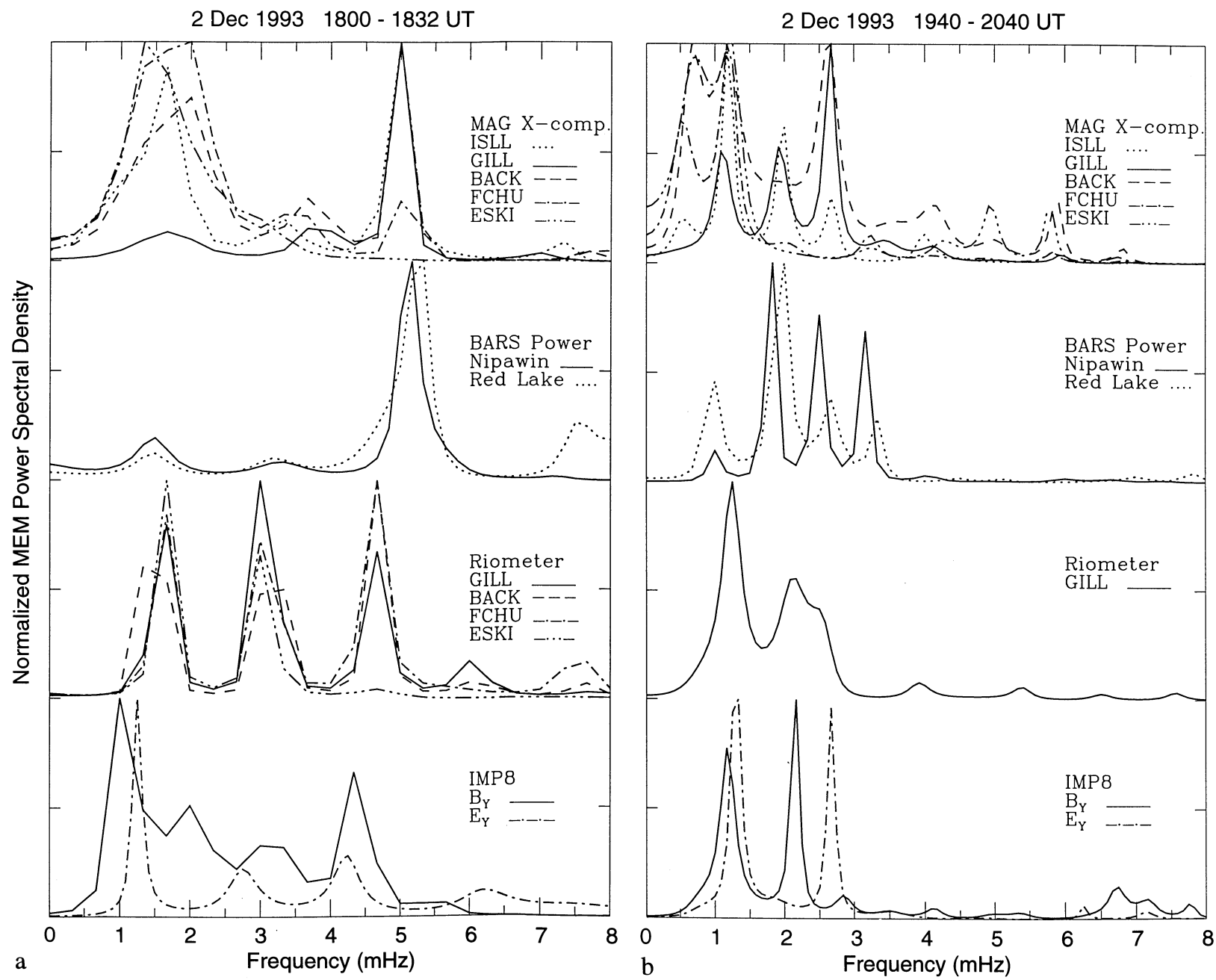

Fig. 11a,b. Normalized MEM power spectra of pure state filtered IMP-8 IMF, riometer absorption, BARS backscatter power, and ground magnetometer data for a event 1 and $\mathbf{b}$ event 2. BARS backscatter power at range gates near BACK (left panel) and GILL (right panel) is used

power spectra showed similar but broad peaks. There is good agreement $( \pm 0.5 \mathrm{mHz})$ between the position of the spectral peaks obtained for the solar wind and ground/ionospheric data. For event 1 , the spectra are dominated by peaks near 1 and $4.5(5) \mathrm{mHz}$ but there is also an intermediate peak near $3 \mathrm{mHz}$ which is particularly strong in the riometer data. The $5-\mathrm{mHz}$ peak corresponds to the short period (3-4 min) oscillations (Fig. 8). For event 2, the spectra show peaks near 1, 2 and $2.5 \mathrm{mHz}$. These peaks are also identified in FFT spectra of the Saskatoon (SuperDARN) radar line-ofsight velocity (Fig. 13; discussed in Sect. 3.6). The BARS radar backscatter spectra (event 2) are somewhat more complex, showing peaks that are slightly downshifted, and include an additional peak near $3 \mathrm{mHz}$. This can be explained by the fact that some of the BARS backscatter bands were actually pairs of bands (e.g., bands $E^{\prime}$ and $E$ ) essentially "doubling" the frequency of the backscatter power oscillations. In general, the correlations in the frequency domain between the IMF and ground/ionosphere oscillations further indicate the presence of an external driver for the observed Pc5 pulsations, i.e., the Alfvén waves in the solar wind. The evidence for externally driven FLRs is presented in the next section.

\subsection{Evidence for FLRS}

The response of the ionosphere to Alfvénic oscillations in the solar wind showed evidence for FLRs. The latitude dependent frequency response and other characteristic FLR signatures during event 1 have already been pointed out in Sect. 3.5. FLR signatures were identified in the ground magnetometer, riometer and radar backscatter signals. It should be noted that this was not possible for all data subsets. For example, there was not enough SuperDARN E-region backscatter during the first pulsation event. BARS Doppler data were not always reliable because of a sidelobe contamination problem (Fig. 8a). Also, note that the F-region SuperDARN backscatter which is usually very useful to look for FLRs (see, e.g., Ruohoniemi et al., 1991) could not be used during this very disturbed event because most of the F-region backscatter was in the polar cap on the open field lines. However, the ground magnetome- 


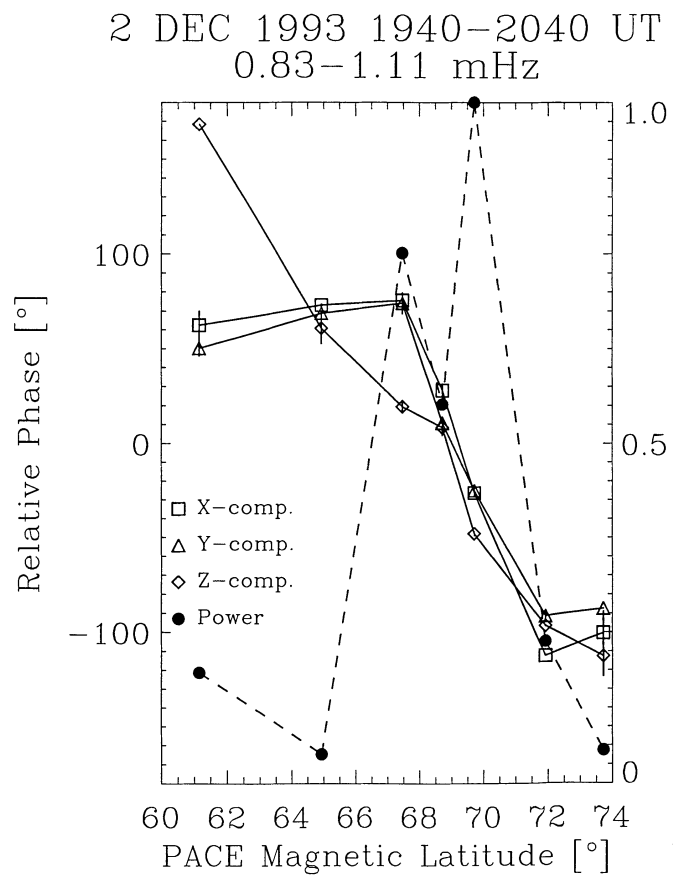

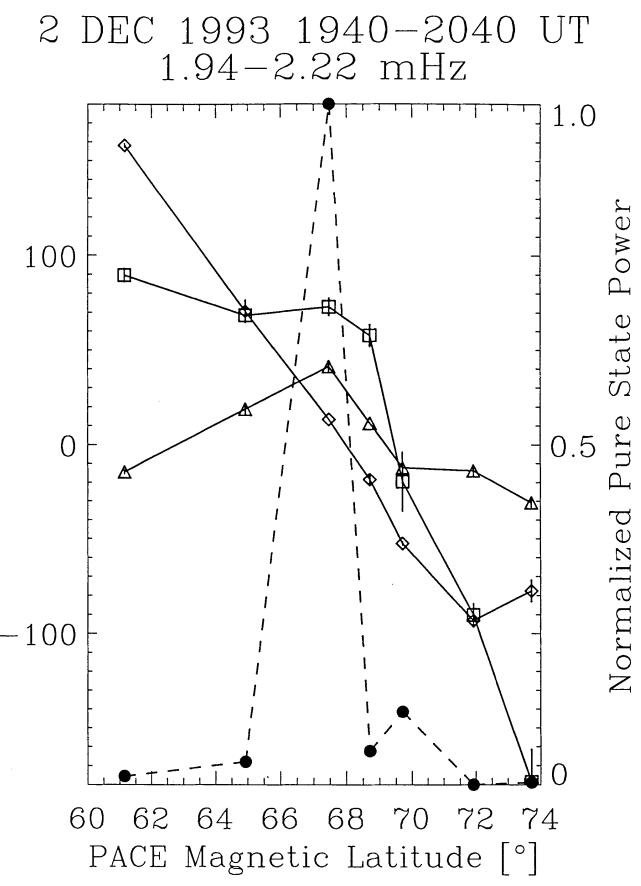

Fig. 12. Poleward phase propagation of 1 and $2-\mathrm{mHz}$ magnetic pulsations. Also, normalized pure state power latitude profiles are shown ter, riometer and E-region radar backscatter data (both SuperDARN and BARS) all showed evidence for FLRs.

Figure 12 shows the results of the spectral analysis of the CANOPUS magnetometer data (7 stations of the north-south array) for event 2 . The magnetometer data were pure state filtered to obtain the relative phase. The phase of the 1 and $2-\mathrm{mHz}$ oscillations decreased with increasing latitude (implying poleward propagation of the perturbations) for all three components across the peak in oscillation power. The FLR signature (Ziesolleck and McDiarmid, 1994) is particularly clear at $1 \mathrm{mHz}$ : the phase of $X$ and $Y$ components decreased by $180^{\circ}$ across the peak in the oscillation power which was located at FCHU while the power of the $2-\mathrm{mHz}$ oscillation peaked at GILL.

SuperDARN radar backscatter was very fragmentary before 2000 UT but solid between 2000 and 2100 UT. Figure 13 shows the spectral analysis results for the Saskatoon SuperDARN radar (beam 11) LoS velocity. These results were obtained using a two-dimensional analysis technique (Fenrich et al., 1995). Three distinct peaks at about 1,2 and $2.5 \mathrm{mHz}$ (the same as those identified in Fig. 11b) can be seen in the spectral power density of the LoS velocity (Fig. 13, top panel). The position of these peaks is clearly latitude dependant, i.e., the highest frequency peak appeared at the lowest latitude and vice versa. The latitude profile of the spectral power at $2 \mathrm{mHz}$ (Fig. 13, bottom panel) shows a peak with halfpower width of about $1^{\circ}$ centered near Gillam. The phase decreased by about $180^{\circ}$ across the latitudinal width of the power peak. However, the phase jump between $66.3^{\circ}$ and $66.7^{\circ}$ is due to a $2 \pi$ phase wrapping (the slope of bands in RTI plots does not reverse). Away from the power peak, the phase continues to change monotonically so that the total phase change between $65^{\circ}$ and $69^{\circ}$ latitude appears to be

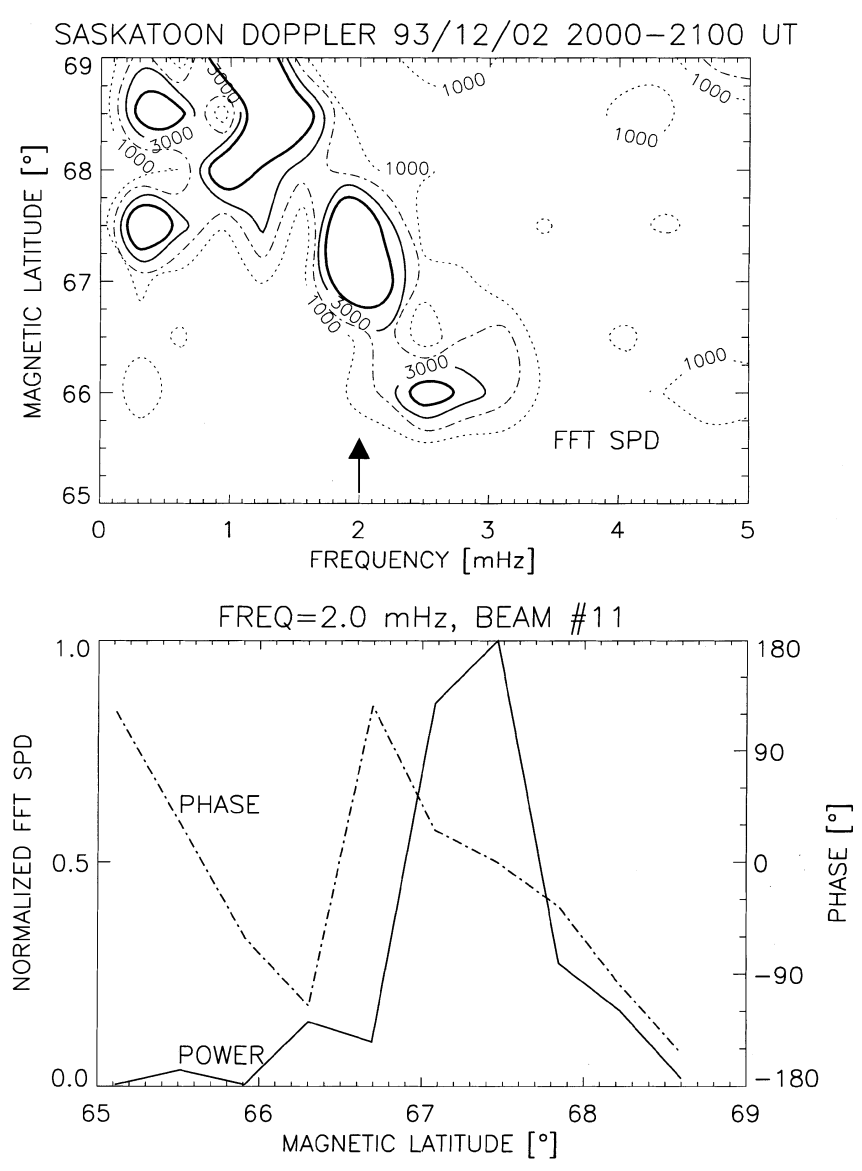

Fig. 13. Contour plots of 32-point fast Fourier transform (FFT) power spectra (top panel) of the line-of-sight velocity time series at several range gates for beam 11 of Saskatoon SuperDARN radar. Also, latitude profiles of the spectral power and phase at $2 \mathrm{mHz}$ are shown (bottom panel) 
considerably larger than $180^{\circ}$. However, the phase estimates at latitudes with low spectral power density must be considered less reliable. We note, though, that field line resonances with a latitudinal phase shift larger than the theoretically predicted $180^{\circ}$ (e.g., Chen and Hasegawa, 1974; Southwood, 1974) have been observed previously at auroral latitudes (see for instance Ziesolleck and McDiarmid, 1994; their Figs. 7 and 15). Also, it should be noted that beam 11 makes an angle with the magnetic meridian; thus any longitudinal phase change will result in a systematic error in the phase dependence on latitude.

The ground magnetic, riometer and radar backscatter signal characteristics (event 1 and 2) are consistent with discrete low-m field line resonances (e.g., Ruohoniemi et al., 1991; Samson et al., 1991, 1992a, b; Ziesolleck and McDiarmid, 1994, 1995; Fenrich et al., 1995). The observed magnetic FLR signatures at frequencies $>1 \mathrm{mHz}$ were not as clear cut as those for the radar/ riometer data. As mentioned in Sect. 3.5, this could be because a magnetometer averages over much larger volume than a radar/riometer and also because of screening of the pulsation signals by the ionosphere (Hughes and Southwood, 1976a, b).

Because the spectra obtained for solar wind and ground/ionospheric data were quite similar (the correlation between the IMF $B_{y}$ component and the ground and ionospheric data has been discussed in Sect. 3.4), we conclude that FLRs were externally (although not necessarily directly) driven by the solar wind Alfvén waves. As we have already noted, the interaction between the Alfvén waves and the bow shock could have generated dynamic pressure oscillations in the magnetosheath which would then excite FLRs.

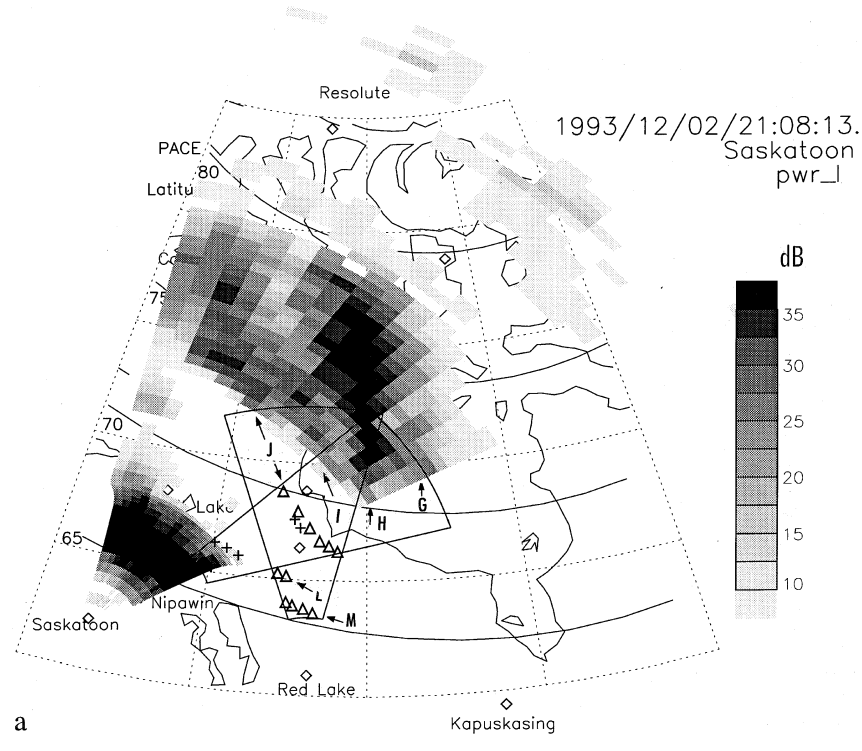

\subsection{The F-region backscatter bands observed by SuperDARN}

The F-region density irregularities that caused the HF radar backscatter are expected to be generated along the equatorward border of the patches by the gradient-drift instability (Tsunoda, 1988). Poleward-progressing Eregion backscatter bands were located near the equatorward edge of the riometer absorption enhancements and showed Doppler spectra indicative of steep horizontal density gradients in auroral arcs. The bands faded away near the cusp latitudes but the remanent Fregion ionization and the steep density gradients provided favorable conditions for production of irregularities in the trailing edges of patches. The F-region backscatter bands observed by SuperDARN were mapped along and/or connected with the E-region backscatter bands (see, e.g., Figs. 14, 16). In other words, the E- and F-region irregularities were associated with (generated by) the same density ridges (gradients) at the equatorward edge of patches at times and/or locations when the patches were formed near the cusp. These density gradients were convected into the polar cap where they continued to generate the F-region irregularities associated with patches. Unfortunately, there were no ionosonde data available from Cambridge Bay and the backscatter bands did not extend as far as Resolute Bay to further provide stronger evidence about the location of the backscatter with respect to patches. However, some of the backscatter bands were associated with equatorward edges of patches observed by the riometer and CADI in RABB after 2000 UT.

Before 1840 UT, the Kapuskasing radar observed three major bands that were detached from the cusp every 10-15 minutes (Fig. 10a). Also, there was an indication of intermediate weaker bands that were

Fig. 14a, b. The Saskatoon SuperDARN radar maps of backscatter power showing the location of patches $(G-K)$ at a 2108 UT and b 2114 UT. The positions of the BARS E-region backscatter bands are shown superposed in the Nipawin (crosses) and Red Lake (triangles) radar fields of view 
similar to those identified in BARS/riometer data (Fig. 8). This backscatter structure appears to be a "fossil" F-region signature of the auroral arcs associated with FLRs that imposed ionization density and gradients (depletions) on the ionospheric structure at auroral latitudes. The flow bursts (FCEs) near the cusp (Figs. 16a, 8c) were similarly modulated (see Sect. 3.8). When patches reached Resolute Bay half an hour later (Fig. 19; discussed below) some of this complex structure was still resolved in the CADI fixed frequency ionograms.

After 2000 UT, many F-region backscatter bands were observed (mainly with the Saskatoon radar; Fig. 10b) and there was a one-to-one correspondence between the E- and F-region bands, which was confirmed by comparing the BARS and SuperDARN radar maps. The patches and associated backscatter bands retained their bandlike form while they drifted in the polar cap. Apparent drift velocities of up to $400 \mathrm{~m} / \mathrm{s}$ for the E-region bands along the BARS Nipawin radar beam 1 were estimated from the slope of the bands in the RTI plots. Because of the tilt of the bands this value is an overestimate of the actual progression speed perpendicular to the bands. In the polar cap, the "fossil" polar patches/bands moved with convection ( $\sim 600 \mathrm{~m} / \mathrm{s}$ as inferred from the translational motion of a series of bands observed with the Saskatoon radar). Just before about 2020 UT the backscatter bands were only slightly tilted with respect to $L$ shells and drifted predominantly poleward. After the IMF $B_{y}$-component turned strongly positive the polar cap convection changed from poleward to north-eastward. The far (west) ends of the bands drifted faster, the bands rotated clockwise, became nearly sun-aligned and eventually drifted eastward. Figure 14 shows two radar maps of backscatter power where a series of bands
$G-K$ is identified at two different times as the bands drifted eastward. At these times, the band $J$ was still observed with BARS at lower latitudes. The gap between the E- and F-region HF backscatter widened because the cusp/cleft (where the enhanced ionization would help the refraction that is needed to intercept field-aligned irregularities) was shifted further equatorward (Figs. 4 and 6b).

Convection maps were obtained by merging the LoS velocities from a pair of SuperDARN radars after 2000 UT (Fig. 15). The direction and magnitude of the convection agreed with the bulk motion of backscatter bands (Fig. 14) derived by tracking individual bands. The 200-s (two-sweep) average radially smoothed velocity maps (Fig. 15) show the initially poleward flow turning eastward. The change of the convection from poleward to eastward at these high latitudes is an expected result of the IMF $B_{y}$-component changing from small values about zero to larger (positive) values after 2020 UT.

SuperDARN observations of backscatter associated with patches spanned the gap between the regions of the patch formation in, or near, the cusp footprint and that of the central polar cap where the patches were observed by ionosondes and a polar camera. At close ranges (E-region and near F-region backscatter) the radar (BARS and SuperDARN) observations provided evidence that the structure imposed on the ionosphere by FLRs was propagated into the polar cap. The large spatial coverage of the radars allowed mapping of the patch related irregularities and the spatial extent of patches/bands could be determined (Sect. 3.10). The convection velocities agreed with the motion of the bands (Fig. 14), optical patches (Fig. 18), and the drift velocities measured by CADIs (briefly discussed in Sect. 3.9).
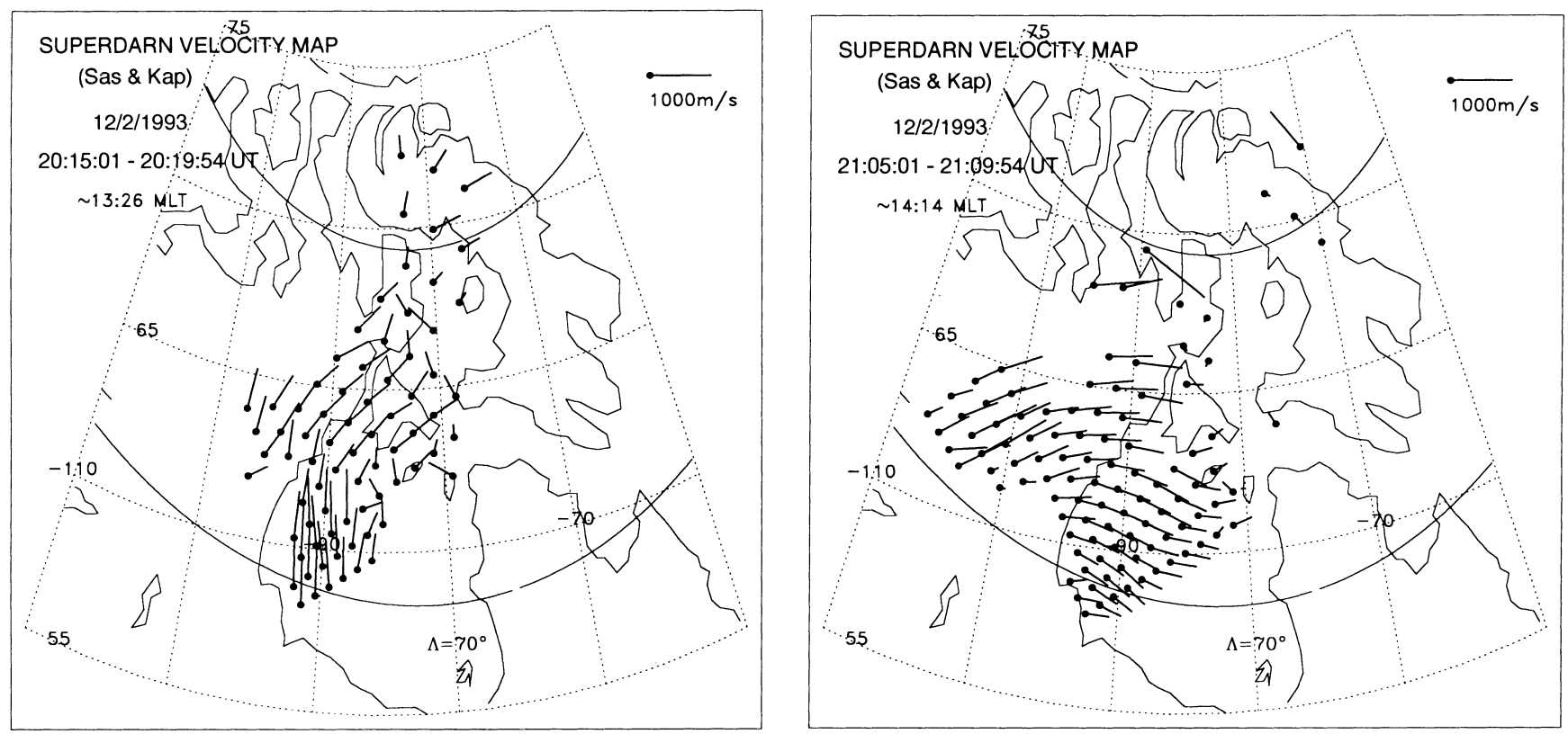

Fig. 15. Polar cap convection observed by the Saskatoon-Kapuskasing pair of radars 


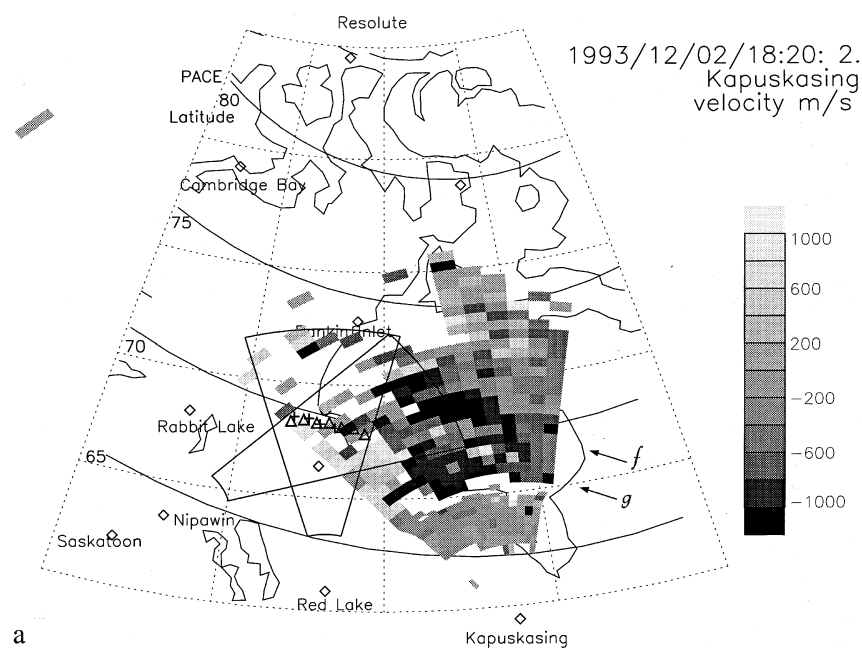

Fig.16a, b. The Kapuskasing SuperDARN radar maps of line-ofsight velocities. a Flow channel events (FCEs) is associated with the BARS E-region backscatter bands $f$ and $g$. Symbols in the BARS field

\subsection{Convection flow bursts (flow channel events)}

Similarly to the case study described in paper 1 SuperDARN observed FCEs that were associated with FLRs. Figure 16 shows examples of FCEs that intesified as the poleward-progressing E-region backscatter bands faded near the cusp footprint. Rodger et al. (1994a) proposed that patches are detached from the cusp by FCEs which produce density depletions in the ionosphere. The results presented here confirm that but also provide evidence that the plasma is "pre-structured" on the closed field lines before it enters into the polar cap as a patch.

Figure 16a shows an FCE near $71^{\circ}$ of magnetic latitude associated with an E-region backscatter band $f$ that had already faded away in the BARS FoV by this time. The LoS flow velocity for this FCE exceeded $1.2 \mathrm{~km} / \mathrm{s}$. Considering the tilt of the flow channel with respect to the radar beams the actual flow along the band likely exceeded $2 \mathrm{~km} / \mathrm{s}$ in this case. Another FCE that has started to form at $69^{\circ}$ magnetic latitude was associated with the next E-region backscatter band $g$ which moved poleward to replace the previous band that had faded away.

Moderately enhanced flow bursts were also observed with the BARS Nipawin radar (Fig. 8c) just poleward of FCHU near the cusp. These E-region flow enhancements preceded FCEs that were observed by the Kapuskasing radar by 1-2 min. It should be noted that the E-region radar measurements often strongly underestimate the actual plasma flows because of the saturation of the Farley-Buneman instability near the ion-acoustic speed (Nielsen and Schlegel, 1985). Just after 1800 UT, the first flow burst appeared to be associated with a couple of weak backscatter bands $a$ and $b$ (observed with BARS) and riometer absorption enhancements progressing poleward (Fig. 8). The next BARS backscatter band $c$ that was associated with relatively strong riometer absorption at lower latitudes faded after it reached

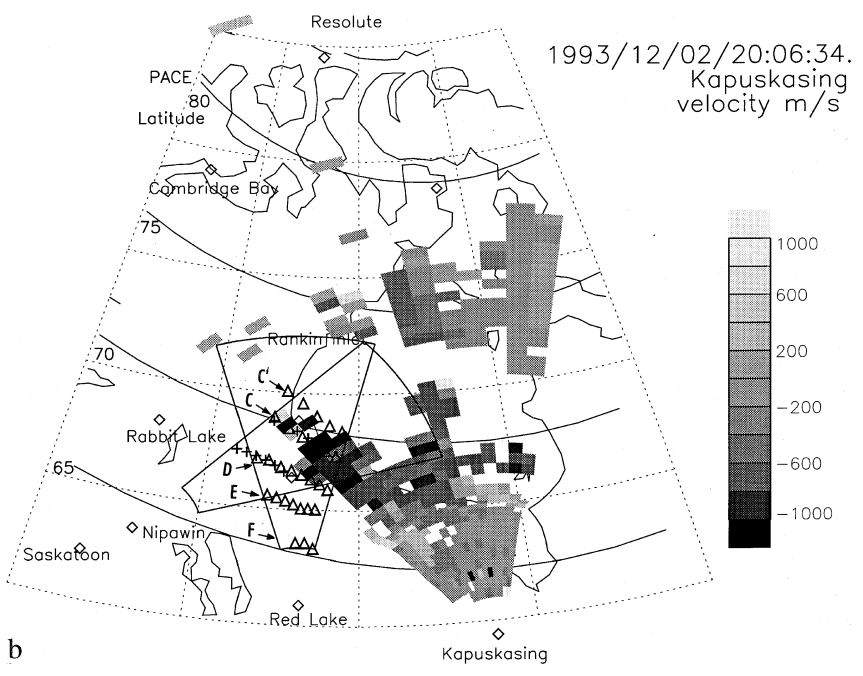

of view indicate the position of the latter band. b Another FCE associated with the E-region backscatter band $C$

FCHU and no significant flow enhancement was observed. The second E-region flow enhancement that spanned bands $d$ and $e$ (later observed by the Kapuskasing radar) originated at rather low latitudes (FCHU) which is consistent with strongly southward IMF (Fig. 8c). However, the next flow burst that was associated with band $f$ was rather inconspicuous in the BARS data while it was quite strong later in the SuperDARN field of view (FOV). The reason for this could have been simply lack of VHF backscatter poleward of FCHU at this time or the FCE that was observed by the Kapuskasing radar (Fig. 16a) originated at somewhat higher latitudes and eastward of BARS field of view. The FCE associated with the band $g$ clearly originated below $68^{\circ}$ magnetic latitude (Fig. 16a). The E-region flow enhancements associated with bands $g$ and $i$ were coincident with the strongest riometer absorption at ESKI and correlated with strongly southward IMF $B_{z}$ suggesting increased reconnection rate. These two FCEs sandwiched a weaker flow burst (band $h$ ) associated with a weak IMF- $B_{y}$ pulse (Fig. 8c) while the IMF $B_{z}$ turned towards zero and then briefly northward.

After 1940 UT (event 2), there were several flow bursts (FCEs) observed with SuperDARN radars (mainly the Kapuskasing radar). At $\sim 1940$ and 1950 UT, two patchy flow bursts $(\sim 1 \mathrm{~km} / \mathrm{s})$ were observed in the western part of the Saskatoon radar associated with the large amplitude fluctuation of $B_{y}$ and possibly with bands $A$ and $B$ (Fig. 6a). The next FCE that started at $\sim 2003$ UT showed an evidence of westward motion of the FCE which is consistent with the expected westward and poleward motion of the FTE signature (e.g., Smith et al., 1992). After a deep negative bay the $B_{y}$ component turned positive again and a high flow burst $(>1 \mathrm{~km} / \mathrm{s}$ ) was associated with the band $C$. Figure $16 \mathrm{~b}$ shows the last of the three consecutive radar scans taken as the flow burst propagated westward with a bulk speed that was comparable with the plasma flow speed. Somewhat weaker FCEs that followed (observed be- 
tween 67 and $68^{\circ}$ magnetic latitude at 2010, 2017, and 2022 UT) were associated with bands $D, E$ and $F$. Later, the F-region backscatter in the western part of the Kapuskasing radar FoV became rather fragmented or completely absent.

As discussed in Sect. 3.5, at least two dominant frequency components/bands $(<2 \mathrm{mHz}$ and $4-5 \mathrm{mHz})$ were identified in the pulsation data between 1800 and 1830 UT (event 1) and these frequencies also modulated the flow bursts. In particular, it was noted that the separations between the strongest flow bursts (Fig. 8c) were 10-11 $\mathrm{min}$ (between $d$ and $g$ ), 7-8 min (e.g., between $g$ and $i$ ) while only 3-4 min separated the weaker flows, e.g., band $h$ from the latter flow bursts. The presence of at least two competing FLR modes (driven by multi frequency IMF oscillations) contributed to some structural complexity of polar patches during event 1. After 1940 UT (event 2), two dominant (and more comensurable) frequency components were $\sim 1$ and $2 \mathrm{mHz}$. The FCEs (as long as they were observed) were associated with individual E-region bands and there was a one-to-one correspondence between the patches and E-region bands.

\subsection{The ionosonde and optical observations of patches}

Figure 17 shows fixed frequency CADI records (virtual height versus time) obtained in Rabbit Lake (RABB; $5 \mathrm{MHz}$ ), Resolute Bay (RESO; $4 \mathrm{MHz}$ ) and Eureka (4 MHz). Between 1800 and 1900 UT the patches above RESO betrayed some of the short-period structure that resulted from the action of FCEs and FLRs as discussed with Fig. 8, but it was not possible to identify individual patches with backscatter bands (Fig. 10a). The CADI signature in Eureka was weak but the 630-nm emission showed irregular patches (not shown) associated with CADI echoes. After the $B_{y}$ IMF became strongly positive no patches were observed by CADIs (particularly at Eureka) until 1930 UT. This is consistent with a change in the polar cap convection due to SvalgardMansurov effect (Cowley et al., 1991). The convective flow towards the dawn sector would send the plasma around flanks of the polar cap and thus prevent patches from reaching the central polar cap. Only a couple of well-separated patches that were most likely associated with two sharp dips in the IMF $B_{y}$ component at 1906 and 1916 UT drifted over Resolute Bay at 1942 and 1951 UT. About 5 min after the patches passed Resolute Bay weak optical signatures were observed in Eureka in $630 \mathrm{~nm}$ (not shown) but the Eureka CADI echoes were too weak at this time.

We will concentrate on the period after 2000 UT (event 2) when most of the patches were observed, particularly at RESO. There was strong absorption before 2000 UT at RABB which was located near the equatorward boundary of the radar cusp (Sect. 3.2) at that time. Although more noisy, the riometer data obtained at RABB were similar to those from GILL (at magnetic latitude $0.5^{\circ}$ south of RABB) showing relatively strong absorption $(\sim 1 \mathrm{~dB})$ before $2000 \mathrm{UT}$. With the absorption being inversely proportional to the square of the frequency this means that at $3 \mathrm{MHz}$ the absorption would have been about $21 \mathrm{~dB}$. In agreement with the inferred absorption, there were virtually no ionosonde echoes before 2000 UT seen by the RABB CADI which

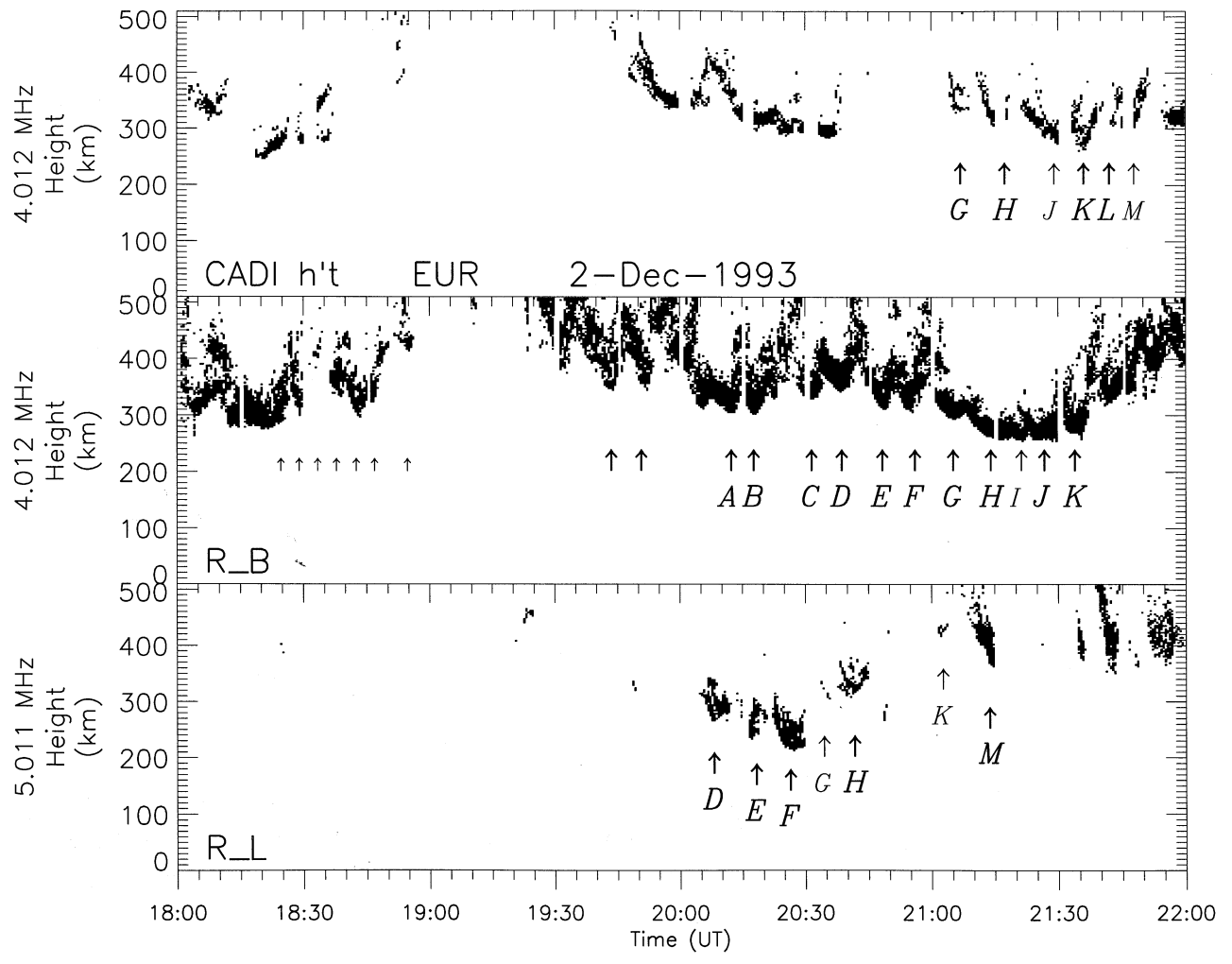

Fig. 17. The fixed frequency ionograms (virtual height versus time) obtained in Rabbit Lake, Resolute Bay and Eureka. The arrows in the top panel indicate times when optical (630-nm) patches passed overhead in $\mathrm{Eu}-$ reka (Fig. 18). The thick arrows in the bottom two panels show polar patches drifting over Rabbit Lake and Resolute Bay that were identified with SuperDARN backscatter bands. The small arrows indicate the short-period structure imposed on the ionosphere by FLRs and/or PMAFs 
had a rather limited dynamic range. At about 2000 UT, when the equatorward boundary of the radar cusp moved near and possibly south of RABB, the absorption decreased and the CADI data on the highest of the fixed frequencies showed a few patches soon after they were formed near the cusp. However, these CADI observations were still somewhat fragmented because of the absorption. Half an hour later the patches were observed drifting northeastward over Resolute Bay and a few more minutes later (almost simultaneously) over Eureka.

After 2000 UT, many bandlike patches that were observed with SuperDARN (Figs. 10b, 4) were also observed with CADIs (Fig. 17) and the all-sky imager (Fig. 18). For example, between 2100 and 2140 UT, CADIs in Resolute Bay and Eureka observed a series of strong patches $(G-K)$ that were seen with SuperDARN at lower latitudes as bands moving eastward (Fig. 14). The transit times of the optical bands (Fig. 18) across the zenith in Eureka (indicated by arrows in the top panel of Fig. 17) were correlated with patches observed with CADI at Eureka. CADI measured horizontal plasma drift velocities for the patches ranging between 500 and $1000 \mathrm{~m} / \mathrm{s}$ northeastward to eastward. The average velocity agreed with the mean translational motion observed by SuperDARN $(\sim 600 \mathrm{~m} / \mathrm{s})$. Note that the latter speed was estimated for the band centers as observed by SuperDARN. The poleward ends of these bands moved faster as they rotated turning eastward with convection.

Figure 19 shows the ionograms, taken at 15-min intervals by the Resolute Bay CADI, over the period 2100-2145 UT. Approximate values of $f x F 2$ are shown for patches and/or troughs separating the patches. The value of $f_{o F} 2$ can be obtained by subtracting $0.8 \mathrm{MHz}$ (half of the electron gyrofrequency). At 2100 UT, oblique echoes from the patch $G$ approaching the zenith and a trough between patch $F$ and $G$ were recorded. At 2115 UT, the center of the patch $H$ was overhead (foF $2 \sim 8.5 \mathrm{MHz})$ indicating the maximum electron density of about $9 \times 10^{11} \mathrm{~m}^{-3}$. This is an increase by a factor of about 4.5 from the trough density estimated in the previous ionogram. The ionogram at 2130 UT

$W^{N} E$

Polar Camera $630.0 \mathrm{~nm} \quad$ O('D) 2 Dec 93

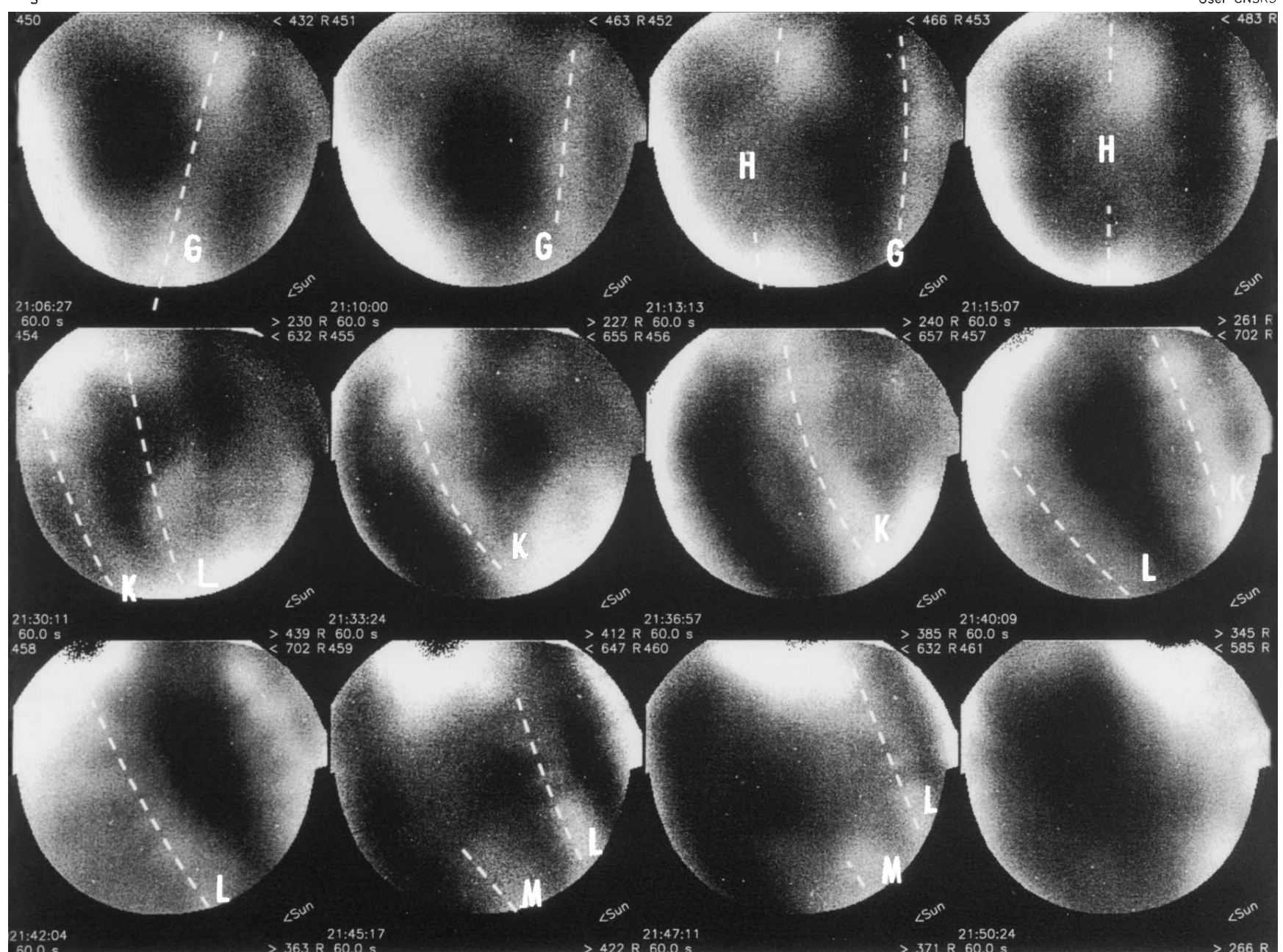

Fig. 18. The 630-nm emission images from the polar camera in Eureka showing patches/bands associated with CADI and SuperDARN observations 


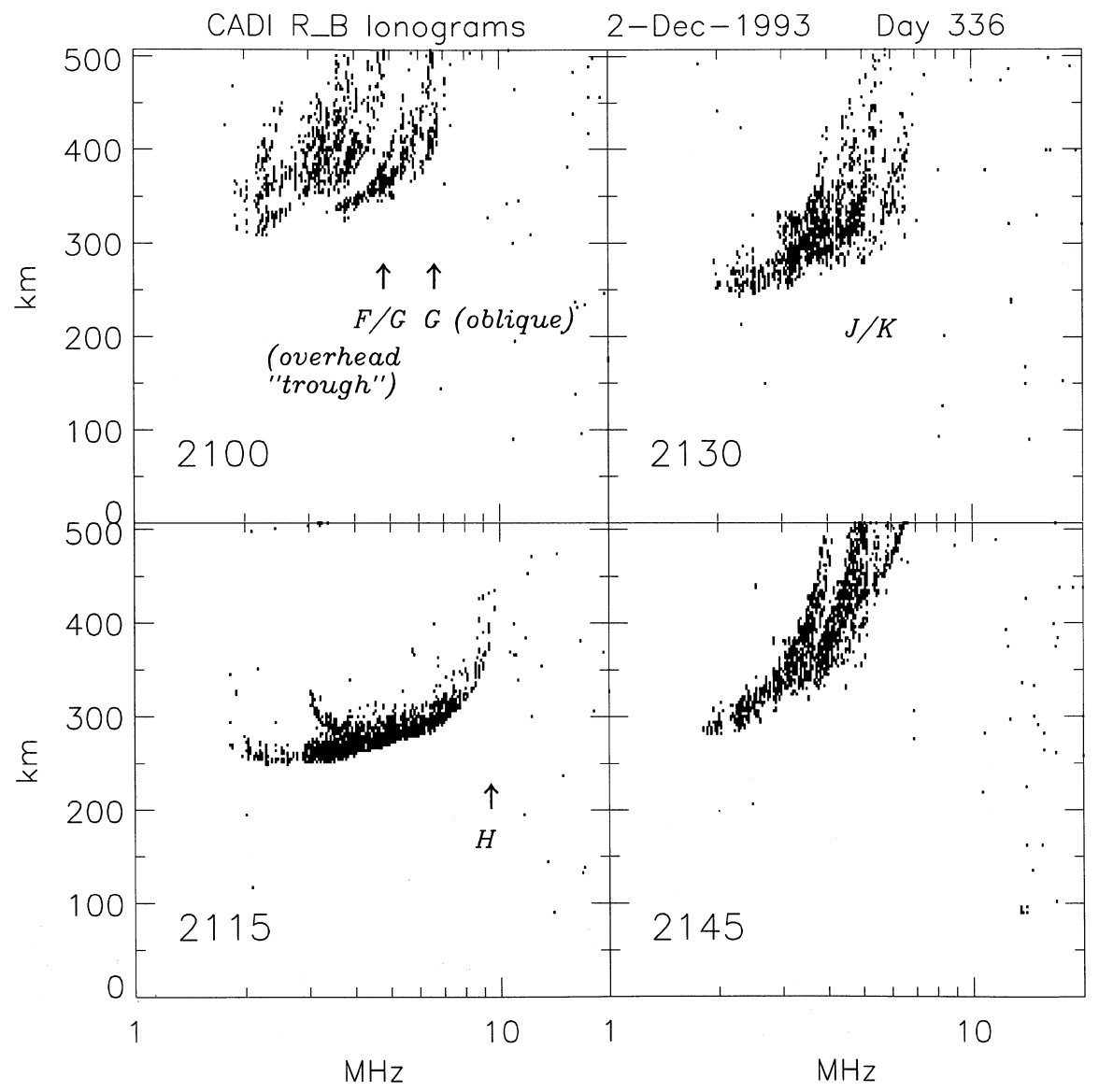

Fig. 19. The Resolute Bay CADI ionograms of polar cap patches and troughs between patches showed spread echoes which were due to oblique echoes from edges of the patch $J$ (receding) and the patch $K$ (approaching). Note that a couple of minutes later the poleward end of the bands $J$ and $K$ swept over Eureka and were also observed optically (Fig. 18).

As mentioned, the RABB CADI observed some patches soon after they formed near the cusp (before 2030 UT). At 2015 UT, a full ionogram (not shown) was taken when the patch $E$ was overhead. It showed almost the same foF 2 value (electron density) as that of the patch $H$ over Resolute Bay (Fig. 19) suggesting that the patches were fully formed in the cusp. Also, there is a possibility that the electron precipitation associated with FLRs contributed to patches. However, as further discussed in Sect. 4.3, the electron precipitation alone is not sufficient to build up enough of the patch ionization relative to the background. In fact, looking at quiet days (November 30 and December 4) the maximum ionization density at RABB between 2000 and 2100 UT would correspond to $f x F 2$ of $8-9 \mathrm{MHz}$ which is not too different from the 9.4-MHz maximum shown for patch $E$ overhead at Rabbit Lake at 2015 UT. Therefore, a combination of a small enhancement due to auroral precipitation on top of the solar EUV ionization and redistribution of the plasma into enhancements and depletions by means of ionospheric currents could explain the patches. Further evidence for restructuring is that the ionization between patches was much lower than quiet day values thus indicating that it had been depleted (see Sect. 4.3). For example, at 2100 UT the
Resolute Bay CADI ionogram showed an F-region peak density corresponding to about $6 \mathrm{MHz}$ at the edge of a patch and $4 \mathrm{MHz}$ in the overhead trough.

The peak electron densities of nearly $10^{12} \mathrm{~m}^{-3}$ (factor $\sim 5$ above the background/trough density) are similar to previous measurements (Weber et al., 1984; Buchau and Reinisch, 1991; Rosenberg et al., 1993; Fukui et al., 1994; Rodger et al., 1994a; Nishino et al., 1998). However, the patches, particularly those observed after 2000 UT, were distinctly bandlike in appearance.

\subsection{The spatial extent of bands/patches}

At $1750 \mathrm{UT}$, the riometer absorption enhancements extended from BACK to FSMI and just before 1800 UT even farther to DAWS ( $>3 \mathrm{~h}$ of local time). In the BARS FoV the absorption enhancements were associated with irregularity bands. The observed F-region patches were more irregular than those observed after 2000 UT (see Sect. 3.7). Also, the optical patches in Eureka were structured and distorted (likely a result of the large amplitude IMF $B_{y}$-component oscillation affecting the polar cap convection).

Figures 14 and 16 show several examples when the Eand F-region radar (BARS and SuperDARN) backscatter bands were joined into one structure extended in azimuth and altitude. The CADI observations in Resolute Bay and Eureka indicated that, as the bands turned eastward, they were extended poleward even 
farther than observed with the SuperDARN radars. Furthermore, the F-region patches were imaged (630nm emission) from Eureka (Fig. 18).

Combining all these observations one can conclude that some of the bands/patches were extended over $\sim 3 \mathrm{~h}$ of local time and/or $2500 \mathrm{~km}$ in observed length. The widths of the backscatter bands were mostly between 100 and $200 \mathrm{~km}$ except for the strongest band $H$ which, at one time, may have been over $300 \mathrm{~km}$ wide in the $\mathrm{F}$ region (Fig. 14a). The widths of the optical and density patches were similar and the separations between neighboring patches were between 200 to $300 \mathrm{~km}$.

\section{Discussion}

\subsection{Dayside poleward moving auroral forms}

Dayside poleward moving auroral forms (PMAFs) are frequently observed near the auroral oval around magnetic local noon (see e.g. Sandholt et al., 1990; Fasel, 1995, and references therein). The arcs appear near the equatorial edge of the auroral oval with a repetition rate ranging from a few to several minutes, drift poleward spanning about two degrees of latitude and then usually brighten and/or disappear. Vorobjev et al. (1975) were first to suggest that these events are the manifestations of the transfer of magnetic field lines from the dayside to the nightside, which are now called FTEs. A statistical study by Fasel (1995) found that the PMAFs have a mean lifetime of $5 \mathrm{~min}$ and that the mean time between successive PMAFs is 6 min. Such PMAF recurring rates, similar to $\mathrm{Pc} 5$ periodicities, were also found by Lockwood et al. (1989) and Sandholt et al. (1990) who called the events dayside auroral break up events or simply cusp/cleft auroral activity (Sandholt et al., 1994). McHarg and Olson (1992) correlated such events with the ULF wave activity and Leontyev et al. (1992) showed magnetometer data for one of their "PMAF" events but did not discuss the associated Pc5 pulsations that can clearly be identified in their Fig. 5 . Lockwood et al. (1989) found that the mean repetition period of the ionospheric flow and auroral burst events is about $8.5 \mathrm{~min}$ when the IMF is continuously and strongly southward. They suggested that transient momentum exchange between the magnetosheath and the ionosphere occurs quasi-periodically with a mean period similar to that of FTE occurrence rate at the magnetopause. More recently, Øieroset et al. (1997) studied signatures of pulsed magnetopause reconnection that included PMAFs during IMF $B_{y}>0$ conditions. The PMAFs events recurred every 5-8 $\mathrm{min}$ and were associated with poleward-progressing geomagnetic disturbances. Just equatorward of PMAFs, short period (2-4 min) pulsations were observed.

While there were no optical data during the daytime event presented here, the similarities of the radar and riometer signatures (near cleft/cusp locations, recurrence rates, lifetimes, and drift velocities) with those of PMAFs are rather suggestive of poleward drifting auroral forms associated with FLRs (Figs. 6a, 8d).
The BARS radar signatures alone (backscatter structure and the Doppler spectra) combined with riometer observations provide strong evidence for the presence of auroral arcs. Even the more subtle details of the motions observed in the radar backscatter agree with the results by Sandholt et al. (1990) and Fasel (1995). These authors described two phases of PMAF evolution. In phase I, the PMAF tends to elongate in the east-west dimension and rapidly moves westward while progressing poleward (Fasel, 1995). During phase II, the PMAF just moves poleward and the optical intensities fades. The BARS radar backscatter exhibited very similar signatures. Shortly after the bands appeared, some of them showed a westward moving intensification along the band. Later the bands just drifted poleward and faded away. Another feature of PMAFs reported by Fasel et al. (1992) is multiple brightenings of a PMAF. The Nipawin radar backscatter power (Figs. 6a, 8b) indicated that some bands (e.g., $f, g$, and $h$ ) showed several intensifications as they progressed poleward. A multiple flaring of poleward drifting arcs and possibly even splitting of such arcs due to higher FLR frequencies that were mentioned (Sect. 3.5) could explain the complex riometer signature (Fig. 8).

\subsection{A link between Pc5 FLRs and dayside magnetic reconnection}

The phenomena (PMAFs, DPY currents, FCEs, and polar patches) that we discussed already have been linked to the process of dayside magnetopause magnetic reconnection, which often appears to be pulsed. In paper 1 , it was shown that compressional MHD waves in the solar wind modulated the magnetic reconnection into pulses, but it was suggested that FLRs might play a role. Similarly, the present results show that FCEs, DPY currents and FLRs can be driven by Alfvén waves in the solar wind. In particular, the dawn-dusk component of the electric field of the Alfvén wave was closely correlated with the poleward-progressing radar backscatter bands associated with FCEs and patches. The cross-correlation analysis and similarity of power spectra between the solar-wind $B_{y}, E_{y}$ and ground/ionospheric data show evidence of an external driver of the observed FLRs and FCEs. We have already mentioned that, although the Alfvénic fluctuations are non-compressive, they can generate dynamic pressure pulses downstream of the bow shock (Lin et al., 1996). The latter authors suggested that the interaction between the solar wind Alfvén waves with the bow shock generates Alfvén waves and large-amplitude pressure pulses in the magnetosheath. Both can play an important role in the coupling process at the magnetopause. While there was no magnetosheath data available on December 2, 1993, time lags of a few minutes or less (Sect. 3.4) that were observed between the solar wind IMF fluctuations and auroral (subcusp) ground/ionospheric pulsations suggest propagation of solar-wind generated disturbances from the subsolar magnetopause to the resonant $L$ shells via the fast compressional mode which would then 
couple to the shear mode driving the resonance. Also, as discussed in paper 1, it is suggested that there is a possibility of a reverse feedback from the resonating magnetic shells near the magnetopause to the reconnection region at the magnetopause (Fig. 1). While the magnetospheric magnetic field oscillations (due to FLRs) were predominantly in the azimuthal direction they contained a significant radial component as well. The amplitudes of the magnetic oscillations on the ground that were discussed in Sect. 3.5 exceeded $100 \mathrm{nT}$ in the $X$ component (corresponding to the azimuthal magnetic field oscillation in the magnetosphere) but reached up to $50 \mathrm{nT}$ in the $Y$ component (corresponding to the radial magnetic field oscillation in the magnetosphere). Thus the electric field component of a resonant Alfvén wave on the outermost closed magnetic flux tubes (see also paper 1) could have modulated the magnitude of the electric field along the reconnection line, i.e., the reconnection rate.

\subsection{Patch formation}

The polar patches have been found to break off from the cusp region shortly after quasiperiodic FCEs (Rodger et al., 1994a) and drift poleward in trains (series of patches separated by a few hundred kilometers) (Foster, 1993; Rosenberg et al., 1993; Nishino et al., 1998). Lockwood et al. (1993) observed the ionospheric signatures of pulsed FTEs and suggested the role of low-energy precipitation in the polar patch formation.

The observations we present showed that polar patches were associated with Pc5 irregularity bands and the bulk of the ionization forming the patch had its origin in the dayside auroral oval which includes both the solar photoionization and auroral precipitation. We suggest that FLR associated precipitation in auroral arcs (PMAFs) drifting into the cusp region, combined with the cusp precipitation and density depletions in regions of strong electric field, can build up significant absolute and/or relative densities in addition to those caused by solar EUV ionization. Weber et al. (1984) proposed the possibility of "spatial resonance", where the plasma and the particle source convect together at the same velocity, thus exposing a flux tube to particle fluxes for several minutes. The coupling of the solar wind Alfvén waves during a period of $B_{z}<0$ could provide such a mechanism if the background antisunward convection becomes comparable to the drift speed of the FLR imposed flow/precipitation pattern. The auroral plasma is then restructured into enhancements and depletions by means of ionospheric currents and enhanced recombination in the $\mathrm{F}$ region. Even if the auroral precipitation does not significantly increase the absolute values of the F-region density, the arcs are likely to be associated with latitudinally narrow, fieldaligned auroral density depletions formed by vertical evacuation in the downward FACs adjacent to an arc (Opgenoorth et al., 1990) which could then lead to greater differences between patch and trough densities. Electron density depletions were observed to be associ- ated with regions of enhanced perpendicular electric fields adjacent to auroral arcs (Opgenoorth et al., 1990). Such density depletions would create the steep density gradients which are required for generation of the ionospheric irregularities associated with patches (Crowley, 1996). If auroral forms drifting across the cusp are signatures of FTEs (Sandholt et al., 1990), the resulting precipitation and associated density depletions would further enhance the absolute and relative densities (gradients) in patches that are formed in the cusp. Signatures of magnetopause reconnection in the spatial distribution of ionospheric densities observed using ionospheric tomography have been identified and related to optical aurora (Walker et al., 1998). Also, it was shown that the plasma density can be depleted by enhanced $\mathrm{O}^{+}$recombination in the $\mathrm{F}$ region (Valladares et al., 1994) and/or by vertical evacuation of electrons in a strong downward FAC (Doe and Vickrey, 1995). These processes would increase the relative density in the patch with respect to the electron density trough formed within the flow channel adjacent to the patch. Incoherent scatter radar measurements (Doe et al., 1993) demonstrated that auroral ionospheric cavities (AICs) with depletions of the F-region densities by $40 \%$ or more can occur on time scales as short as $4 \mathrm{~min}$. Valladares et al. (1994; see their Figs. 4b, 5b) presented Sondrestrom incoherent scatter radar data which showed density structures resembling auroral arcs being drawn into the cusp footprint prior to the onset time of the fast plasma jet which they associated with enhanced ion temperature and $\mathrm{O}^{+}$recombination rate. These poleward-progressing local density enhancements $\left(\sim 5 \times 10^{11} \mathrm{~m}^{-3}\right)$ that were a few hundred kilometers apart in the north-south direction of the elevation scans were most likely produced by auroral arcs. The F-region density enhancements that can be inferred from the elevation scans range up to $50 \%$. Similar F-region density enhancements (associated with riometer absorptions) in series of plasma patches drifting from the cusp to the polar cap were observed by EISCAT incoherent scatter radar (Nishino et al., 1998).

In general agreement with the conclusions by Lockwood et al. (1993), we suggest that patches observed on December 2, 1993 were generated by FTEs during times of southward IMF. It appears that the magnetic reconnection at the dayside magnetopause was pulsed by the dawn-dusk component of the electric field associated with an Alfven wave in the solar wind and possibly also by the electric field associated with the solar-wind-driven FLR in the magnetic shell adjacent to the magnetopause. The patches were a by-product of this coupling process. The FLR driven arcs and/or associated density structure of remanent F-region density enhancements/depletions convected into the ionospheric cusp where the plasma was reformed by cusp precipitation and FCEs producing even more pronounced density enhancements/depletions. This process would eliminate some while it may reinforce other parts of the short period FLR structure that was imposed on the ionosphere prior to the entry to the cusp. For example, during the first event presented here $(1800$ 
1830 UT), the reconnection associated flows in the cusp were modulated by low frequencies $(1-2 \mathrm{mHz})$, thus reshaping the FLR imposed high frequency $(4-5 \mathrm{mHz})$ structure into patches that were more irregular. After 1930 UT, patches were produced by a (more harmonious) combined action of $1-$ and $2 \mathrm{mHz}$ FLR/FCE modulation of flows and densities near the cusp which resulted in patches that were identified with individual flow bursts and FLR backscatter bands.

We have associated the patch formation with poleward-progressing DPY currents (Hall currents associated with FCEs). A large statistical data base of DPY current observations was accumulated by Stauning et al. (1994). The longitudinal and latitudinal extents of the DPY Hall currents that are most intense in the region between the downward and upward field-aligned current sheets are comparable with the observed separations between the patches. The horizontal electric fields associated with the convection enhancements (FCEs) result in the E-region electron heating which can explain the radio wave absorption near the cusp (Stauning et al., 1995). A gradual fading of DPY currents as they traverse the dayside polar cap could explain the riometer absorption associated with polar patches (Rosenberg et al., 1993). The absence of DPY events for northward IMF is consistent with the absence of patches during such periods (Rodger et al., 1994a). If the link between the poleward-progressing DPY currents and polar patches is confirmed, this mechanism of patch formation could be identified as a dominant source of patches, considering the abundance of the $B_{y}$-modulated DPY events (Stauning et al., 1994).

We have referred to several possible sources of ionization and/or mechanisms for patch formation. Now we briefly summarize their relative importance. The electron density given by the International Reference Ionosphere (IRI) 1990 model for an altitude of $250 \mathrm{~km}$ above Gillam at 2000 UT near solar minimum (mean sunspot number 60) is $7 \times 10^{11} \mathrm{~m}^{-3}$ and drops to $4 \times 10^{11} \mathrm{~m}^{-3}$ at $400 \mathrm{~km}$. With the cusp and auroral oval sunlit the solar EUV ionization is the main source of the large background density onto which auroral and cusp ionization is superposed (Roble and Rees, 1977). Sojka and Schunk (1986) considered the effect of discrete auroral precipitation on the density profile and found large density enhancements (see their Fig. 3) within a few minutes of a plasma flux tube entering a region of auroral precipitation.

Another mechanism we consider is redistribution of ionization by currents. To estimate the electron densities we assume an electric field $\pm 50 \mathrm{mV} / \mathrm{m}$ and a standard value for ion mobility of 50 (MKS units) at an altitude of $250 \mathrm{~km}$. From BARS data showing bands associated with FCEs, we estimated the wavelength of the electric field variation to be $\sim 150 \mathrm{~km}$ ( 2 cycles in $300 \mathrm{~km})$. Also, we assume that it takes $\sim 15 \mathrm{~min}$ for the bands to traverse a $300-\mathrm{km}$ wide cusp. The corresponding drift velocity is consistent with the poleward drift velocity inferred from the BARS backscatter (see Sect. 3.7) and in good agreement with the mean drift velocity $(\sim 350 \mathrm{~m} / \mathrm{s})$ measured by CADI in RABB just before
2030 UT. Then the relative plasma "relocation" by currents can be estimated from the charge continuity equation to be $\sim 10 \%$. This is comparable to the auroral precipitation, because it would cause both an enhancement and a depletion of density (i.e., relative enhancement of 20\%). Doe et al. (1995) modeled the formation of auroral ionospheric cavities (AICs), showing that FACs are very efficient at modifying the polar ionosphere. They showed that moderate downward FACs $\left(0.2 \mu \mathrm{A} \mathrm{m}^{-2}\right)$ can create a $40 \%$ depletion in time scales of $30 \mathrm{~s}$, while diffusion and chemistry operate on longer time scales (hundreds of seconds). These authors suggested that "cavities are created by closure of downward magnetospheric field-aligned currents and that AIC-arc pairs are the imprint of an oppositely directed pair of FACs". This mechanism of density depletion appears to be directly applicable to FLRs which are associated with a pair of oscillatory FACs. Similarly, the signature of an FTE footprint (FCE) implies oppositely directed FACs (Southwood et al., 1988). While the horizontal dimensions of FCEs are about one order of magnitude larger than those of the AICs modeled by Doe et al. (1995), the latter authors showed that the narrow and fast-growing depletion regions can grow to larger widths by allowing more time to build them up.

\section{Conclusions}

Elongated ionization patches were observed with CADI ionosondes and an all-sky imager in the polar cap. SuperDARN (HF) and BARS (VHF) radars, along with the CANOPUS magnetometers and riometers, were used to trace the origin of polar patches to the ionospheric regions near and just equatorward of the cusp footprint during a period of southward IMF. Ionospheric and ground signatures of intense coupling between the solar wind Alfvén waves (identified in the IMP-8 magnetic field and plasma data) and the dayside magnetosphere were observed. These signatures included flow channel events (FCEs), poleward-progressing DPY currents, and field line resonances (FLRs) that were manifested by poleward-progressing ground magnetic perturbations, riometer absorptions and radar backscatter bands. It is suggested that the FLRs were associated with precipitation (poleward moving auroral forms, PMAFs). The cross-correlation of the ground and ionospheric data with the IMF $B_{y}$ showed evidence that these Pc5 pulsations were driven by Alfvénic oscillations in the solar wind. In particular, FLRs were driven by the IMF- $B_{y}$ oscillations, as were DPY currents in and poleward of the cusp. Near the cusp, the poleward-progressing backscatter bands were associated with FCEs and were closely correlated with the dawndusk component of the inferred solar wind electric field, which is expected to modulate the reconnection rate at the subsolar magnetopause. Polar patches were a byproduct of the coupling process which could have included compressional oscillations generated by the 
solar wind Alfvén waves downstream of the bow shock in the magnetosheath.

The F-region ionosphere, pre-structured by FLRs (auroral precipitation, density depletions and gradients), was segmented into polar patches by FCEs carving out electron depletions while the soft cusp precipitation inferred from the riometer data augmented the density of the patch formed poleward (IMF $B_{y}>0$ ) of the flow channel. Also, as previously reported, it is likely that the F-region $\mathrm{O}^{+}$recombination loss associated with the enhanced flows further depleted the trough densities between patches. The density patches which were structured by irregularities produced by density gradients at the equatorward edge of the patches had a large longitudinal extent spanning $\sim 3 \mathrm{~h}$ of local time $(\sim 2500 \mathrm{~km})$ but were only $\sim 200 \mathrm{~km}$ wide. It is concluded that the solar EUV ionization, significantly augmented by the auroral/cusp ionization and prestructured by FLRs, was reformed into bandlike patches by FCEs redistributing the ionization into enhancements and depletions by means of ionospheric/field aligned currents, while the field lines were being reconnected to the IMF and convected into the polar cap.

Acknowledgements. The CANOPUS program is a project of the Canadian Space Agency. The CADI and polar camera installations and operations were funded by the Canadian Network of Space Research. The Kapuskasing radar is supported by NASA Grant NAG5-1099. The Saskatoon radar is funded by an NSERC CSP Grant. We acknowledge the contributions by A. Lazarus (MIT) and R. Lepping (NASA, Goddard Space Flight Center) who made available the IMP-8 data and by F. Rich (Phillips Laboratory, Hanscom Air Force Base) who provided us with DMSP satellite data and helped with their interpretation. We gratefully acknowledge use of the Arctic Stratospheric Ozone Laboratory (Eureka, NWT), a facility of Environment Canada's Atmospheric Environment Service, and instrument operation support provided by the University of Saskatchewan. The FLR analysis software for SuperDARN data was provided by F. Fenrich (University of Alberta). A. McNamara and D. Wallis (National Research Council of Canada) assisted us in evaluation of the BARS and riometer data, respectively. We also benefited from discussions with D. McDiarmid, T. Hughes, G. James, R. Jenkins, A. Rodger, J. Samson, A.D.M. Walker, and C.W.S. Ziesolleck.

Topical Editor K.-H. Glassmeier thanks W. Lotko and another referee for their help in evaluating this paper.

\section{References}

Anderson, D. N., J. Buchau, and R. A. Heelis, Origin of density enhancements in the winter polar cap ionosphere, Radio Sci., 23, 513-519, 1988.

André, D., A. G. McNamara, D. D. Wallis, B. A. McIntosh, T. J. Hughes, G. J. Sofko, J. A. Koehler, D. R. McDiarmid, P. Prikryl, and J. Watermann, Diurnal radio aurora variations at $50 \mathrm{MHz}$ measured by the Bistatic Auroral Radar System radars, J. Geophys. Res., 93, 8651-8661, 1988.

Baker, K. B., J. R. Dudeney, R. A. Greenwald, M. Pinnock, P. T. Newell, A. S. Rodger, N. Mattin, and C.-I. Meng, HF radar signatures of the cusp and low-latitude boundary layer, J. Geophys. Res., 100, 7671-7695, 1995.

Banks, P. M., T. Araki, C. R. Clauer, J.-P. St-Maurice, and J. C. Foster, The interplanetary electric field, cleft currents, and plasma convection in the polar caps, Planet. Space Sci., 32, 1551-1557, 1984.
Basu, S., Su. Basu, P. K. Chaturvedi, and C. M. Bryant, Jr., Irregularity structures in the cusp/cleft and polar cap regions, Radio Sci., 29, 195-207, 1994.

Belcher, J. W., and L. Davis, Jr., Large-amplitude Alfvén waves in the interplanetary medium, 2, J. Geophys. Res., 76, 3534-3563, 1971.

Buchau, J., and B. W. Reinisch, Electron density structures in the polar F region, Adv. Space Res., 11(10), 29, 1991.

Buchau, J., B. W. Reinisch, E. J. Weber, and J. G. Moore, Structure and dynamics of the winter polar cap F region, Radio Sci., 18, 995-1010, 1983.

Buchau, J., E. J. Weber, D. N. Anderson, H. C. Carlson, Jr., J. G. Moore, B. W. Reinisch, and R. C. Livingston, Ionospheric structures in the polar cap: their origin and relation to $250-\mathrm{MHz}$ scintillation, Radio Sci., 20, 325-338, 1985.

Chen, L., and A. Hasegawa, A theory of long-period magnetic pulsations, 1, steady state excitation of field line resonance, J. Geophys. Res., 79, 1024-1032, 1974.

Clauer, C. R., and P. M. Banks, Relationship of the interplanetary electric field to the high-latitude ionospheric electric field and currents: observations and model simulation, J. Geophys. Res., 91, 6959-6971, 1986.

Clauer, C. R., P. M. Banks, A. Q. Smith, T. S. Jorgensen, E. FriisChristensen, S. Vennerstrom, V. B. Wickwar, J. D. Kelly, and J. Doupnik, Observation of interplanetary magnetic field and of ionospheric plasma convection in the vicinity of the dayside polar cleft, Geophys. Res. Lett., 1, 891-894, 1984.

Clauer, C. R., P. Stauning, T. J. Rosenberg, E. Friis-Christensen, P. M. Miller, and R. J. Sitar, Observations of a solar-wind-driven modulations of the dayside ionospheric DPY current system, J. Geophys. Res., 100, 7697-7713, 1995.

Cowley, S. W. H., and M. Lockwood, Excitation and decay of solar-wind driven flows in the magnetosphere-ionosphere system, Annales Geophysicae, 10, 103-115, 1992.

Cowley, S. W. H., J. P. Morelli, and M. Lockwood, Dependence of convective flows and particle precipitation in the high-latitude dayside ionosphere on the $X$ and $Y$ components of the interplanetary magnetic field, J. Geophys. Res., 96, 5557-5564, 1991.

Crooker, N. U., Dayside merging and cusp geometry, J. Geophys. Res., 84, 951-959, 1979.

Crooker, N. U., F. R. Toffoletto, and M. S. Gussenhoven, Opening the cusp, J. Geophys. Res., 98, 263, 1991.

Crowley, G., Critical review of ionospheric patches and blobs, in Ed. W. Ross Stone Review of Radio Science 1993-1996, Oxford University Press, New York, pp. 619-648, 1996.

Doe, R. A. and J. F. Vickrey, Electrodynamic model for the formation of auroral ionospheric cavities, J. Geophys. Res., 100, 9683-9696, 1995.

Doe, R. A., M. Mendillo, J. F. Vickrey, L. Zanetti, and R. Eastes, Observations of nightside auroral cavities, J. Geophys. Res., 98, 263, 1993.

Fairfield, D. H., Average and unusual locations of the Earth's magnetopause and bow shock, J. Geophys. Res., 76, 6700-6716, 1971.

Farley D. T., and B. G. Fejer, The effect of the gradient drift term on the type 1 electrojet irregularities, J. Geophys. Res., 80, 30873090, 1975.

Fasel, G. J., Dayside poleward moving auroral forms: a statistical study, J. Geophys. Res., 100, 11891-11905, 1995.

Fasel, G. J., J. I. Minow, R. W. Smith, C. S. Deehr, and L. C. Lee, Multiple brightenings of transient dayside auroral forms during oval expansions, Geophys. Res. Lett., 12, 2429-2432, 1992.

Fenrich, F. R., J. C. Samson, G. Sofko, and R. A. Greenwald, ULF high and low-m field line resonances observed with SuperDARN, J. Geophys. Res., 100, 21535-21547, 1995.

Foster, J. C., Storm time plasma transport at middle and high latitudes, J. Geophys. Res., 98, 1675-1689, 1993.

Foster, J. C., and J. R. Doupnik, Plasma convection in the vicinity of the dayside cleft, J. Geophys. Res., 89, 9107-9113, 1984. 
Fukui, K., J. Buchau, and C. E. Valladares, Convection of polar cap patches observed at Qaanaaq, Greenland, during the winter 1989-1990, Radio Sci., 29, 231-248, 1994.

Friis-Christensen, E., and J. Wilhjelm, Polar cap currents for different directions of the interplanetary magnetic field in the YZ plane, J. Geophys. Res., 80, 1248-1260, 1975.

Grant, I. F., J. W. MacDougall, J. M. Ruohoniemi, W. A. Bristow, G. J. Sofko, J. A. Koehler, D. Danskin, and D. André, Comparison of plasma flow velocities determined by the ionosonde Doppler drift technique, SuperDARN radars, and patch motion, Radio Sci., 30, 1537-1549, 1995.

Greenwald, R. A., K. B. Baker, J. M. Ruohoniemi, J. R. Dudeney, M. Pinnock, N. Mattin, J. M. Leonard, and R. P. Lepping, Simultaneous conjugate observations of dynamic variations in high-latitude dayside convection due to changes in IMF $B_{y}$, J. Geophys. Res., 95, 8057-8072, 1990.

Greenwald, R. A., K. B. Baker, J. R. Dudeney, M. Pinnock, T. B. Jones, E. C. Thomas, J.-C. Villain, J.-C. Cerrisier, C. Senior, C. Hanuise, R. D. Hunsucker, G. Sofko, J. Koehler, E. Nielsen, R. Pellinen, A. D. M. Walker, N. Sato, and H. Yamagishi, DARN/ SUPERDARN: a global view of the dynamics of high-latitude convection, Space Sci. Rev., 71, 761-796, 1995.

Hall, G., D. R. Moorcroft, L. L. Cogger, and D. André, Spatial relationship between large aspect angle VHF radio aurora and 557.7-nm emission: evidence from refraction, J. Geophys. Res., 95, 15281-15288, 1990.

Hassam, A. B., Transmission of Alfvén waves through the earth's bow shock: theory and observation, J. Geophys. Res., 83, 643653,1978

Hughes, T. J., and G. Rostoker, Current flow in the magnetosphere and ionosphere during periods of moderate activity, J. Geophys. Res., 82, 2271-2282, 1977.

Hughes, W. J., and D. J. Southwood, The screening of micropulsation signals by the atmosphere and ionosphere, J. Geophys. Res., 81, 3234-3240, 1976a.

Hughes, W. J., and D. J. Southwood, An illustration of modification of geomagnetic pulsation structure by the ionosphere, J. Geophys. Res., 81, 3241-3247, 1976 b.

International Reference Ionosphere 1990, URSI/COSPAR, National Space Science Data Center/World Data Center A for Rockets and Satellites, Rep. 90-22, 1990.

Lin, Y., L. C. Lee, and M. Yan, Generation of dynamic pressure pulses downstream of the bow shock by variations in the interplanetary magnetic field orientation, J. Geophys. Res., 101, 479-493, 1996.

Leontyev, S. V., G. V. Starkov, V. G. Vorobjev, V. L. Zverev, and Y. I. Feldstein, Dayside aurorae and their relation to other geophysical phenomena, Planet. Space Sci., 40, 621-639, 1992.

Lockwood, M., The case for transient magnetopause reconnection, Eos, Trans., 77, 246-250, 1996.

Lockwood, M., and H. C. Carlson, Jr., Production of polar cap electron density patches by transient magnetopause reconnection, Geophys. Res. Lett., 19, 1731-1734, 1992.

Lockwood, M., P. E. Sandholt, S. W. H. Cowley, and T. Oguti, Interplanetary magnetic field control of dayside auroral activity and the transfer of momentum across the dayside magnetopause, Planet. Space Sci., 67, 1347-1365, 1989.

Lockwood, M., W. F. Denig, A. D. Farmer, V. N. Davda, S. W. H. Cowley, and H. Luhr, Ionospheric signatures of pulsed reconnection at the Earth's magnetopause, Nature, 361, 424-428, 1993.

MacDougall, J. W., I. F. Grant, and X. Shen, The Canadian Advanced Digital Ionosonde: design and results, in "Report $U A G$-14: Ionospheric Networks and Stations", World Data Center A for Solar-Terrestrial Physics, 21, 1995.

McHarg, M. G., and J. V. Olson, Correlated optical and ULF magnetic observations of the winter cusp - boundary layer system, Geophys. Res. Lett., 19, 817-820, 1992.

McKenzie, J. F., and K. O. Westphal, Transmission of Alfvén waves through the Earth's bow shock, Planet. Space Sci., 17, 1029-1037, 1969.
McNamara, A. G., D. R. McDiarmid, G. J. Sofko, J. A. Koehler, P. A. Forsyth, and D. R. Moorcroft, BARS - a dual bistatic auroral radar system for the study of electric fields in the Canadian sector of the auroral zone, Adv. Space Res., 2, 145-148, 1983.

Newell, P. T. and Ch. -I. Meng, Ionospheric projections of magnetospheric regions under low and high solar wind pressure conditions, J. Geophys. Res., 99, 273-286, 1994.

Newell, P. T., D. G. Sibeck, and Ch.-I. Meng, Penetration of the interplanetary magnetic field $B y$ and magnetosheath plasma into the magnetosphere: implications for the predominant magnetopause merging site, J. Geophys. Res., 100, 235-243, 1995.

Nielsen, E., and K. Schlegel, Coherent radar Doppler measurements and their relationship to the ionospheric electron drift velocity, J. Geophys. Res., 90, 3498-3504, 1985.

Nishino, M., S. Nozawa, and J. A. Holtet, Daytime ionospheric absorption features in the polar cap associated with poleward drifting F-region plasma patches, Earth Planet. Space, 50, 107 117, 1998.

Opgenoorth, H. J., I. Haggstrom, P. J. S. Williams, and G. O. L. Jones, Regions of strongly enhanced perpendicular electric fields adjacent to auroral arcs, J. Atmos. Terr. Phys., 52, 449-458, 1990.

Øieroset, M., P. E. Sandholt, H. Lühr, W. F. Denig, and T. Moretto, Auroral and geomagnetic events at cusp/mantle latitudes in the prenoon sector during positive IMF $B_{y}$ conditions: Signatures of pulsed magnetopause reconnection, J. Geophys. Res., 102, 7191-7205, 1997.

Pinnock, M., A. S. Rodger, J. R. Dudeney, K. B. Baker, P. T. Newell, R. A. Greenwald, and M. E. Greenspan, Observations of an enhanced convection channel in the cusp ionosphere, J. Geophys. Res., 98, 3767-3776, 1993.

Pinnock, M., A. S. Rodger, and K. B. Berkey, High-latitude Fregion electron concentration measurements near noon - a case study, J. Geophys. Res., 100, 7723-7729, 1995a.

Pinnock, M., A. S. Rodger, J. R. Dudeney, F. Rich, and K. B. Baker, High spatial and temporal resolution observations of the ionospheric cusp, Annales Geophysicae, 13, 919-925, 1995b.

Prikryl, P., and L. L. Cogger, Statistical analysis of the spatial relationship between the radio and optical aurora: further evidence for refraction, Radio Sci., 27, 469-479, 1992.

Prikryl, P., G. J. Sofko, J. A. Koehler, J. Mu, and D. André, Steep electron density gradients associated with discrete aurorae explaining the diversity of auroral VHF doppler spectra, Annales Geophysicae, 13, 25-37, 1995.

Prikryl, P., R. A. Greenwald, G. J. Sofko, J. P. Villain, C. W. S. Ziesolleck, and E. Friis-Christensen, Solar-wind-driven pulsed magnetic reconnection at the dayside magnetopause, Pc5 compressional oscillations and field line resonances, J. Geophys. Res., 103, 17 307-17 322, 1998.

Roble, R. G., and M. H. Rees, Time-dependent studies of the aurora: effects of particle precipitation on the dynamic morphology of ionospheric and atmospheric properties, Planet. Space. Sci., 25, 991-1010, 1977.

Rodger, A. S., and A. C. Graham, Diurnal and seasonal occurrence of polar patches, Annales Geophysicae, 14, 533-537, 1996.

Rodger, A. S., M. Pinnock, J. R. Dudeney, K. B. Baker, and R. A. Greenwald, A new mechanism for polar patch formation, J. Geophys. Res., 99, 6425-6436, 1994a.

Rodger, A. S., M. Pinnock, J. R. Dudeney, J. Watermann, O. de la Beaujardiere, and K. B. Baker, Simultaneous two hemisphere observations of the presence of polar patches in the nightside ionosphere, Annales Geophysicae, 12, 642-648, 1994b.

Roelof, E. C., and D. G. Sibeck, Magnetopause shape as a bivariate function of interplanetary magnetic field $B_{z}$ and solar wind dynamic pressure, J. Geophys. Res., 98, 21 421-21 450, 1993.

Rosenberg, T. J., Z. Wang, A. S. Rodger, J. R. Dudeney, and K. B. Baker, Imaging riometer and HF radar measurements of drifting $\mathrm{F}$ region electron density structures in the polar cap, J. Geophys. Res., 98, 7757-7764, 1993.

Rostoker, G., J. C. Samson, F. Creutzberg, T. J. Hughes, D. R. McDiarmid, A. G. McNamara, A. Vallance Jones, D. D. Wallis, 
L. L. Cogger, CANOPUS - a ground-based instrument array for remote sensing the high-latitude ionosphere during the ISTP/GGS program, Space Sci. Rev., 71, 743-760, 1995.

Ruohoniemi, J. M., R. A. Greenwald, K. B. Baker, and J. C. Samson, HF radar observations of Pc5 field line resonances in the midnight/early morning MLT sector, J. Geophys. Res., 96, 15 697-15 710, 1991.

Samson, J. C., Pure states, polarized waves, and principal components in the spectra of multiple, geophysical time-series, Geophys. J. R. Astron. Soc., 72, 647-664, 1983a.

Samson, J. C., The reduction of sample-bias in polarization estimators for multichannel geophysical data with anisotropic noise, Geophys. J. R. Astron. Soc., 75, 289-308, 1983b.

Samson, J. C., and J. V. Olson, Some comments on the descriptions of the polarization states of waves, Geophys. J. R. Astron. Soc., 61, 115-129, 1980

Samson, J. C., R. A. Greenwald, J. M. Ruohoniemi, T. J. Hughes, and D. D. Wallis, Magnetometer and radar observations of magnetohydrodynamic cavity modes in the earth's magnetosphere, Can. J. Phys., 69, 929-937, 1991.

Samson, J. C., B. G. Harrold, J. M. Ruohoniemi, and A. D. M. Walker, Field line resonances associated with MHD waveguides in the magnetosphere, Geophys. Res. Lett., 19, 441-444, 1992a.

Samson, J. C., D. D. Wallis, T. J. Hughes, F. Creutzberg, J. M. Ruohoniemi, and R. A. Greenwald, Substorm intensifications and field line resonances in the nightside magnetosphere, J. Geophys. Res., 97, 8495-8518, 1992 b.

Sandholt, P. E., M. Lockwood, T. Oguti, S. W. H. Cowley, K. S. C. Freeman, B. Lybekk, A. Egeland, and D. M. Willis, Midday auroral breakup events and related energy and momentum transfer from the magnetosheath, J. Geophys. Res., 95, 10391060, 1990.

Sandholt, P. E., C. J. Farrugia, L. F. Burlaga, J. A. Holtet, J. Moen, B. Lybekk, B. Jacobsen, D. Opsvik, A. Egeland, R. Lepping, A. J. Lazarus, T. Hansen, A. Brekke, and C. FriisChristensen, Cusp/cleft auroral activity in relation to solar wind dynamic pressure, interplanetary magnetic field $B_{z}$ and $B_{y}$, J. Geophys. Res., 99, 17 323-17 342, 1994.

Scholer, M., and J. W. Belcher, The effect of Alfvén waves on MHD fast shocks, Solar Phys., 16, 472-483, 1971.

Sibeck, D. G., K. Takahashi, S. Kokubun, T. Mukai, K. W. Ogilvie, and A. Szabo, A case study of oppositely propagating Alfvénic fluctuations in the solar wind and magnetosheath, Geophys. Res. Lett., 24, 3133-3136, 1997.

Smith, M. F., M. Lockwood, and S. W. H. Cowley, The statistical cusp: a flux transfer event model, Planet. Space Sci., 40, 12511268, 1992.

Sojka, J. J., and R. W. Schunk, A theoretical study of the production and decay of localized electron density enhancements in the polar ionosphere, J. Geophys. Res., 91, 3245-3253, 1986.

Sojka, J. J., M. D. Bowline, R. W. Schunk, D. T. Decker, C. E. Valladares, R. Sheehan, D. N. Anderson, and R. A. Heelis, Modeling polar cap F-region patches using time varying convection, Geophys. Res. Lett., 20, 1783-1786, 1993.

Sojka, J. J., M. D. Bowline, and R. W. Schunk, Patches in the polar ionosphere: UT and seasonal dependence, J. Geophys. Res., 99, 14 959-14 970, 1994.
Southwood, D. J., Some features of field line resonances in the magnetosphere, Planet. Space Sci., 22, 483-491, 1974.

Southwood, D. J., C. J. Farrugia, and M. A. Saunders, What are flux transfer events?, Planet. Space Sci., 36, 503-508, 1988.

Stauning, P., E. Friis-Christensen, O. Rasmussen, and S. Vennerstrom, Progressing polar convection disturbances: signature of a open magnetosphere, J. Geophys. Res., 99, 11 303-11 317, 1994.

Stauning, P., C. R. Clauer, T. J. Rosenberg, E. Friis-Christensen, and R. Sitar, Observations of solar-wind-driven progression of interplanetary magnetic field $B_{y}$-related dayside ionospheric disturbances, J. Geophys. Res., 100, 7567-7585, 1995.

Steele, D. P., and L. L. Cogger, Polar patches and the "tongue of ionization", Radio Sci., 31, 667-677, 1996.

St.-Maurice, J.-P., P. Prikryl, G. J. Sofko, A. Kustov, J. A. Koehler, D. Danskin, A. Hamza, and J. Chen, On the origin of narrow non-ion-acoustic coherent radar spectra in the highlatitude E region, J. Geophys. Res., 99, 6447-6474, 1994.

Taguchi, S., M. Sugiura, J. D. Winningham, and J. A. Slavin, Characterization of the IMF $B_{y}$-dependent field-aligned currents in the cleft region based on DE 2 observations, J. Geophys. Res., 98, 1393-1407, 1993.

Tsunoda, R. T., High-latitude Fregion irregularities: a review and synthesis, Rev. Geophys., 26, 719-760, 1988.

Valladares C. E., S. Basu, J. Buchau, and E. Friis-Christensen, Experimental evidence for the formation and entry of patches into the polar cap, Radio Sci., 29, 167-194, 1994.

Valladares C. E., D. T. Decker, R. Sheehan, and D. N. Anderson, Modeling the formation of polar cap patches using large plasma flows, Radio Sci., 31, 573-593, 1996.

Vorobjev, V. G., G. Gustafsson, G. V. Starkov, Y. I. Feldstein, and N. F. Shevnina, Dynamics of day and night aurora during substorms, Planet. Space Sci., 23, 269-278, 1975.

Walker, A. D. M., R. A. Greenwald, and K. B. Baker, HF radar observations of pulsations near the magnetospheric cusp, J. Geophys. Res., 91, 8919-8928, 1986.

Walker, I. K., J. Moen, C. N. Mitchell, L. Kersley, and P. E. Sandholt, Ionospheric effects of magnetopause reconnection observed using ionospheric tomography, Geophys. Res. Lett., 25, 293-296, 1998.

Watermann, J., Refraction of $50-\mathrm{MHz}$ dara waves in a realistic ionospheric model, Radio Sci., 25, 805-812, 1990.

Weber E. J., J. Buchau, J. G. Moore, J. R. Sharber, R. C. Livingston, J. D. Winningham, and B. W. Reinisch, F Layer ionization patches in the polar cap, J. Geophys. Res., 89, 16831694, 1984.

Weber, E. J., J. A. Klobuchar, J. Buchau, H. C. Carlson, Jr., R. C. Livingston, O. de la Beaujardiere, M. McCready, J.G. Moore, and G. J. Bishop, Polar cap F layer patches: Structure and dynamics, J. Geophys. Res., 91, 12 121-12 129, 1986.

Ziesolleck, C. W. S., and D. R. McDiarmid, Auroral latitude Pc 5 field line resonances: quantized frequencies, spatial characteristics, and diurnal variation, J. Geophys. Res., 99, 5817-5830, 1994.

Ziesolleck, C. W. S., and D. R. McDiarmid, Statistical survey of auroral latitude Pc5 spectral and polarization characteristics, J. Geophys. Res., 100, 19299-19312, 1995. 